\title{
DEVELOPING AND BUILDING A LEAN BASED RFID ELECTRONIC KANBAN PROTOTYPE
}

\author{
A Thesis \\ presented to \\ The Faculty of California Polytechnic State University \\ In Partial Fulfillment \\ of the Requirements for the Degree \\ Master of Science in Industrial Engineering \\ by \\ Ryan T. Chang \\ June 2012
}


(C) 2012

Ryan Chang

ALL RIGHTS RESERVED

COMMITTEE MEMBERSHIP 


\title{
ELECTRONIC KANBAN PROTOTYPE
}

\author{
AUTHOR: \\ Ryan T. Chang
}

DATE SUBMITTED:

June 2012

COMMITTEE CHAIR:

Dr. Tali Freed, Professor, Industrial and

Manufacturing Engineering

COMMITTEE MEMBER: Dr. Lizabeth Schlemer, Associate Professor, Industrial and Manufacturing Engineering

COMMITTEE MEMBER: Dr. Tao Yang, Professor, Industrial and Manufacturing Engineering

ABSTRACT

DEVELOPING AND BUILDING A LEAN BASED 


\title{
RFID ELECTRONIC KANBAN PROTOTYPE
}

\author{
Ryan T. Chang
}

The kanban system is a popular Toyota lean manufacturing tool used to help facilitate material movement between workstations and suppliers. Since the 1950's, the original kanban system has undergone many different variations due to the advancement of technology and unique company implementation. This report focuses on the development and building of a new variation of the kanban system using lean principles while integrating radio frequency identification (RFID) technology with a fully electronic based kanban card system. This new type of kanban system will be called the RFID E-Kanban in this report. Since the lean philosophy is to reduce non-value added waste to a process, the new prototype kanban system meets four design objectives that are consistent with the principles of lean and the original purpose of the kanban system.

1. The RFID E-Kanban prototype must support the process of continuous improvement

2. The RFID E-Kanban prototype must reduce overall non-value added waste to the material flow process

3. The RFID E-Kanban prototype must be intuitive and simple to use for the operator

4. The RFID E-Kanban prototype control must be decentralized

In an applied case study, a RFID E-Kanban prototype was built for a Department of Defense facility involving the movement of chemicals between two locations.

\section{Table of Contents}

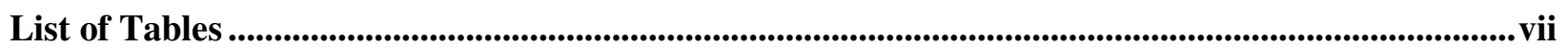

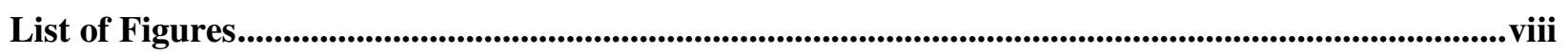

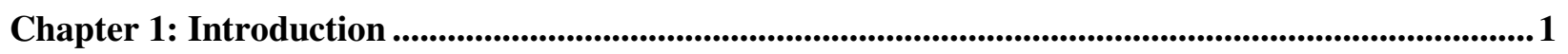

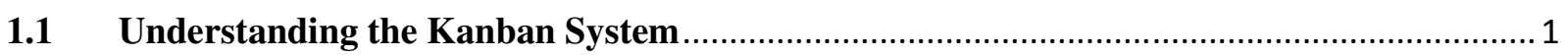




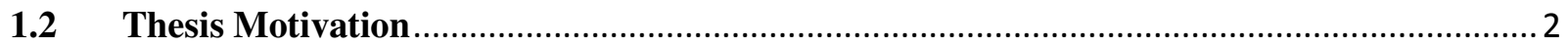

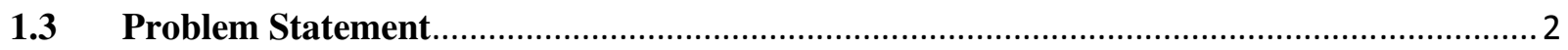

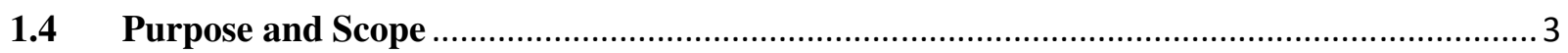

Chapter 2: Background and Literature Review ................................................................................4

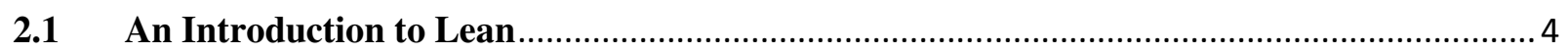

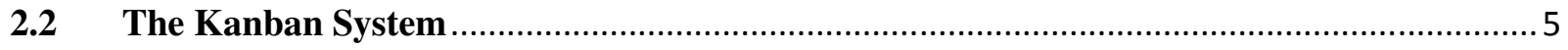

$2.3 \quad$ Radio Frequency Identification (RFID) ..................................................................... 7

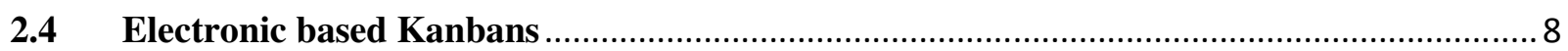

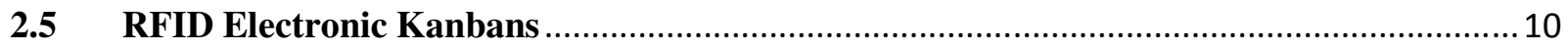

Chapter 3: Methodology ...................................................................................................................................................... 11

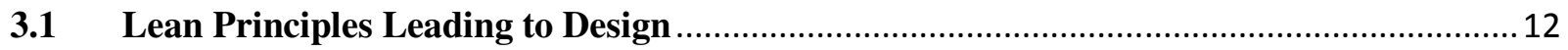

3.1.1 Identifying Lean Attributes in the Original Kanban System.................................... 12

3.1.2 Identify General Lean Principles and Design Concepts ............................................ 13

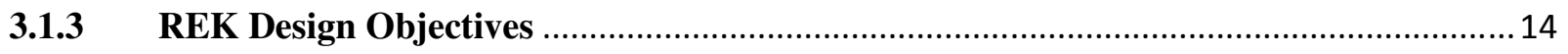

3.2 Identifying Unique Facility Requirements for an RFID Based Kanban Solution ..............16

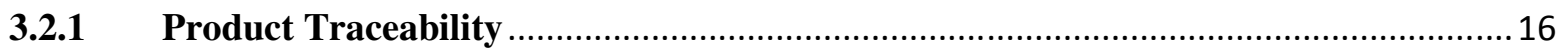

3.2.2 Automatic Scanning and Location Tracking ........................................................ 17

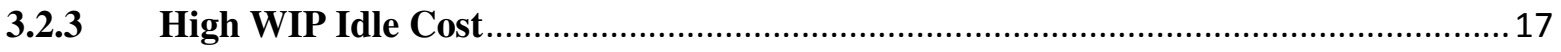

3.3 Determining the Quantity of Kanban Cards ............................................................. 17

Chapter 4: The General REK Model Overview................................................................................................... 18

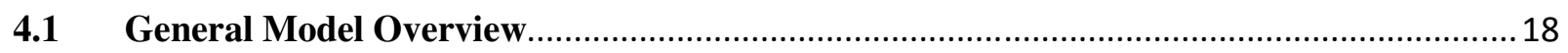

4.2 Production Kanban Process Workflow..................................................................... 19

4.2.1 Production Kanban Process Framework ................................................................ 21

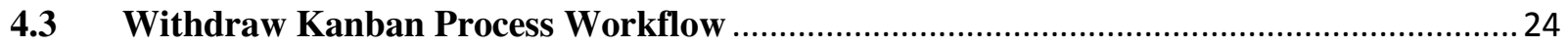

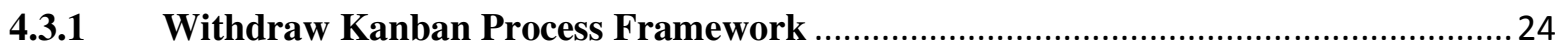

Chapter 5: Results and Case Study ..........................................................................................................................28

$5.1 \quad$ Background on Department of Defense Facility Case Study ….......................................28

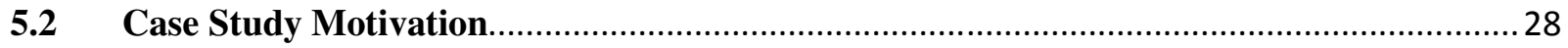

5.3 Consideration of Lean Challenges Involving Chemical Inventory Tracking ....................29

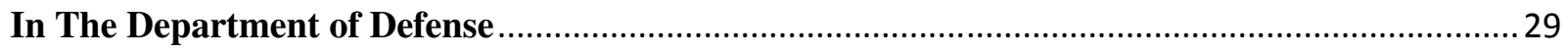

5.4 Physical Considerations for RFID Configuration and Setup .......................................... 31

5.4.1 Chemical Movement Between the Storage and Foundry Area ................................... 31 


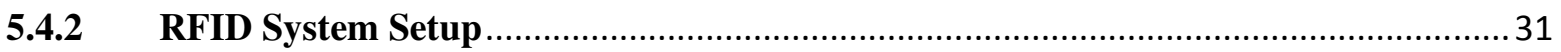

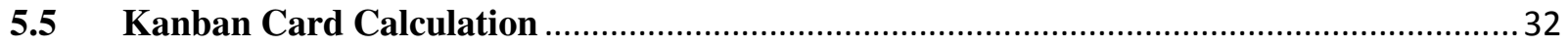

5.6 Adapting the REK General Model to the DoD facility .................................................. 32

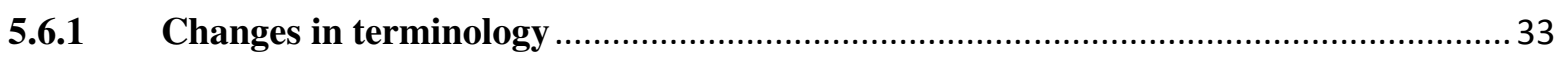

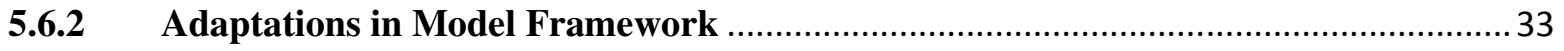

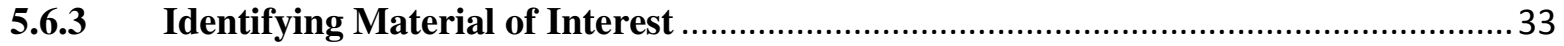

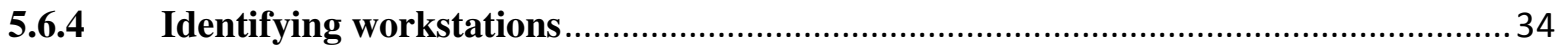

5.6.5 Added Functionality: Recording Container History …........................................ 34

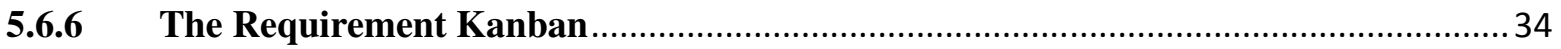

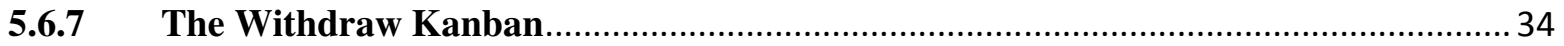

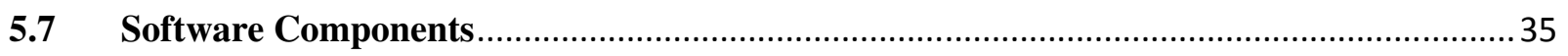

5.7.1 Programming Language C\# .NET ….................................................................... 35

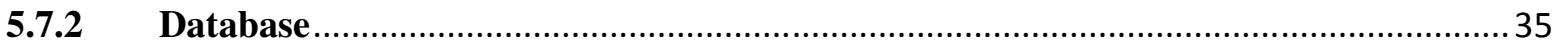

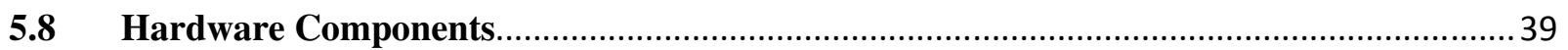

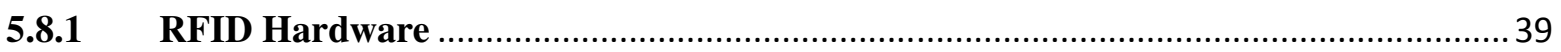

$5.9 \quad$ Hardware and Software Development Location ............................................................ 39

5.10 ChemTRACE prototype Graphical User Interface (GUI) Description ............................ 40

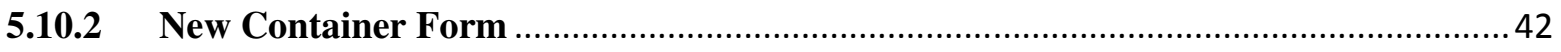

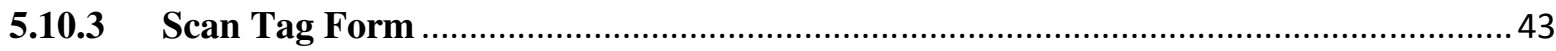

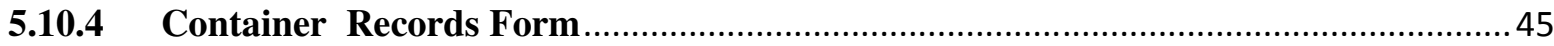

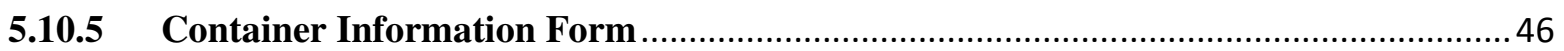

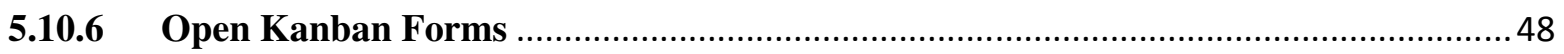

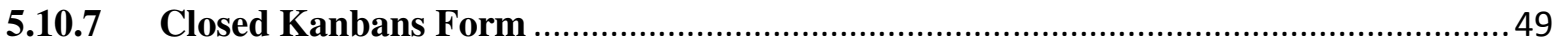

5.10.8 Requirement Kanban Card Form ................................................................... 50

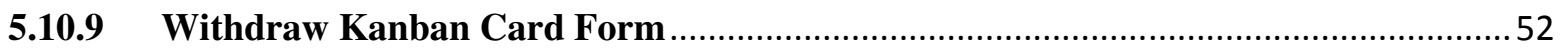

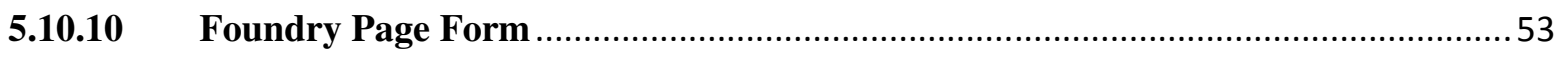

5.10.11 Create Requirement Kanban Form ….............................................................. 54

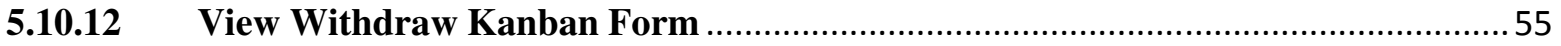

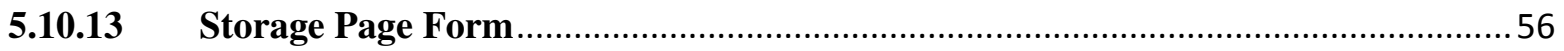

5.10.14 View Requirement Kanban Request Form...................................................... 57

5.10.15 Create Withdraw Kanban Request Form.......................................................... 58

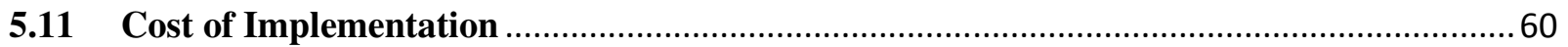




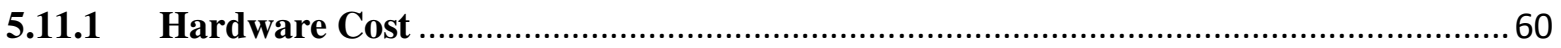

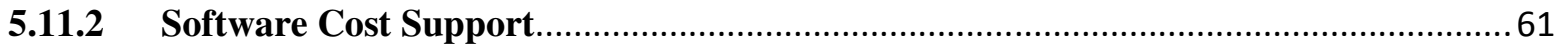

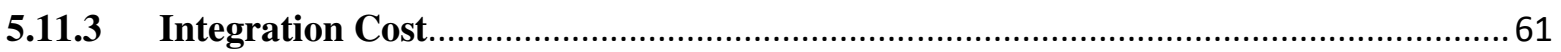

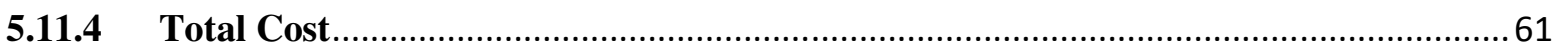

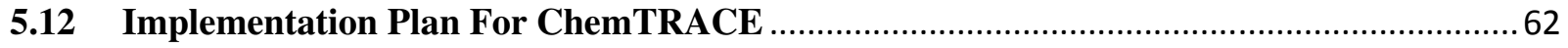

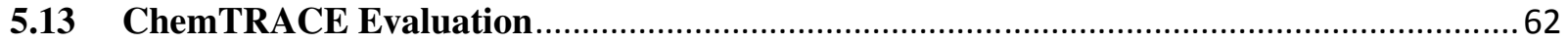

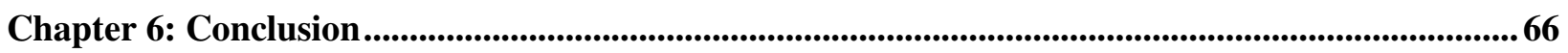

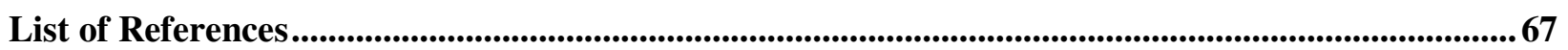

Appendix A: Production Kanban Operator Workflow.........................................................................70

Appendix B: Withdraw Kanban Operator Workflow .......................................................................72

Appendix C: Cotton, Keith, Personal Communication ................................................................................. 74

Appendix D: Selected ChemTRACE Software Code ............................................................................... 75

\section{List of Tables}

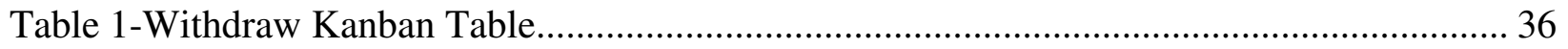

Table 2-Production (Requirement) Kanban Table............................................................. 37

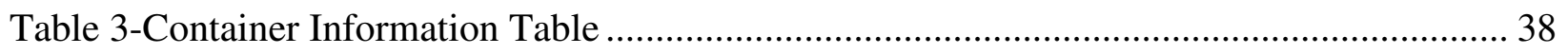




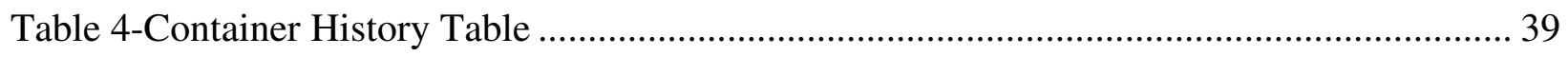

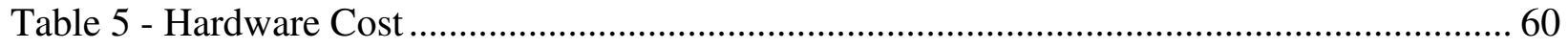

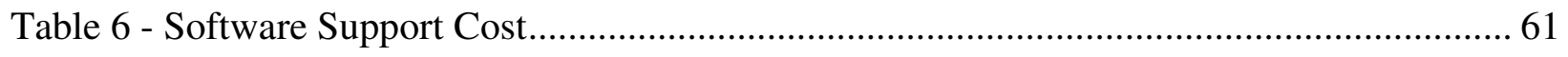

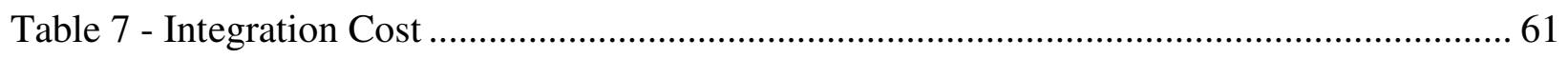

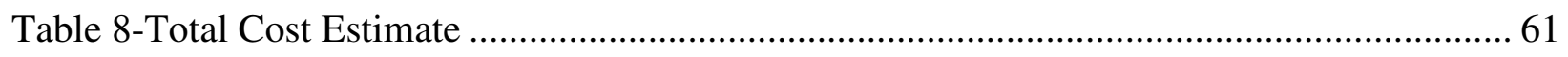

\section{List of Figures}

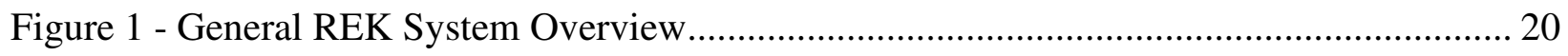

Figure 2-Production Kanban Process Framework ......................................................... 22

Figure 3-Withdraw Kanban Process Framework............................................................. 25 


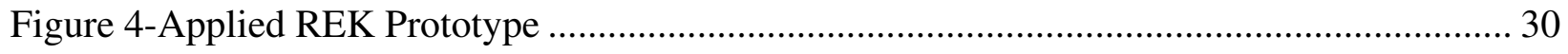

Figure 5 - Layout of Chemical Storage Unit and Foundry Area.................................................. 31

Figure 6-Main Form Screen................................................................................................ 40

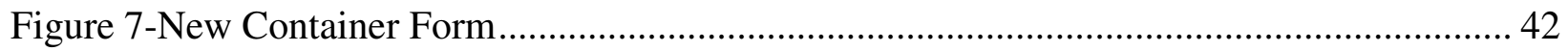

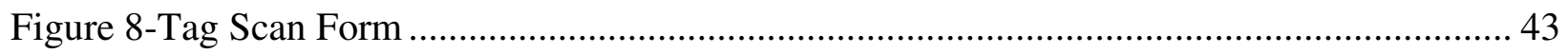

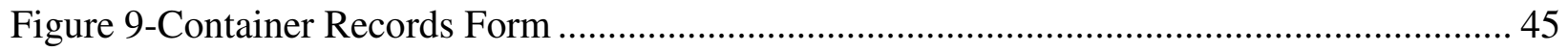

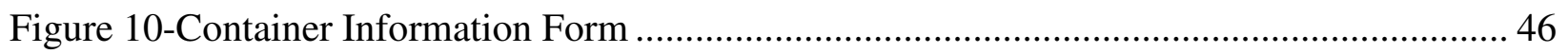

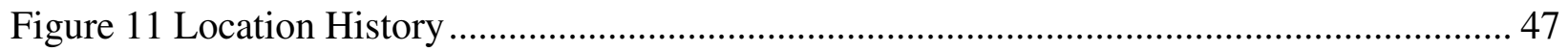

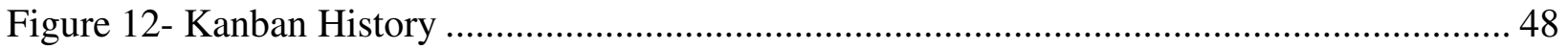

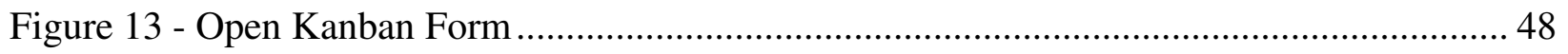

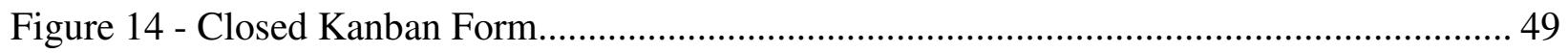

Figure 15 - Requirement Kanban Form …………......................................................... 50

Figure 16 - Requirement Kanban Card with Withdraw Option.................................................... 51

Figure 17 - Withdraw Kanban Card Form ............................................................................. 52

Figure 18 - Foundry Page Form......................................................................................... 53

Figure 19 - Create Requirement Kanban Form......................................................................... 54

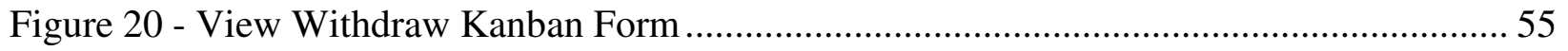

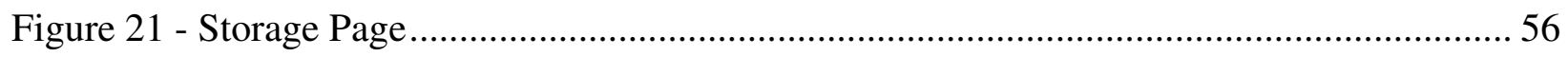

Figure 22 - View Requirement Kanban Request Form .............................................................. 57

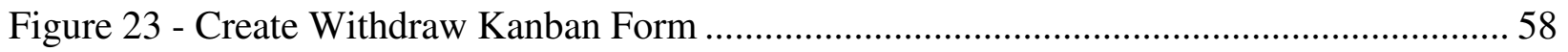




\section{Chapter 1: Introduction}

\subsection{Understanding the Kanban System}

The kanban system is a material flow system that seeks to manage the production of products by controlling the proper quantity of material at the proper time, in order to minimize the amount of excess inventory. The kanban system is a widely known and popular "pull" control system in Toyota's Production Just-In-Time (JIT) manufacturing system.

At the heart of the kanban system is the use of the kanban card. The kanban card is a signal that is used at every step in the production process when materials need to be produced or moved. The kanban card itself contains any relevant instructions and information that the operator would need in order to produce or move material.

In a basic two-bin kanban system, there are two types of cards: the production card and the withdraw card. The production card contains any relevant information regarding the production of the material while the withdraw card contains any relevant information of where the material should be moved and when. When workstation A needs material from workstation $\mathrm{B}$, a production kanban will be generated by workstation A to be given to workstation B. When workstation B has produced the desired material, workstation B will generate a withdraw kanban authorizing the movement of the material to workstation A. How the kanban cards are delivered to and from workstations differ from one company to another. It is a common practice however, to have logistic delivery operators periodically check each workstation to see if there is a production kanban or withdraw kanban that needs to be delivered or returned. These logistic delivery operators may also move the material given there is a withdraw kanban card attached to the material. 


\subsection{Thesis Motivation}

In the past two decades there has been increasing interest in a fairly recent variation of the kanban system, the electronic kanban (e-kanban). Even today, companies are still in the process of switching to e-kanban. In the field of Radio Frequency Identification (RFID) technology, there also has been increasing interest for manufacturers to use this developing technology to improve operation effectiveness and control. The concept of an RFID integrated e-kanban is one of the newest variations of the kanban system. However, there is not much literature describing in detail the development of such a system or its framework. This report aims to provide insightful and useful information on the approach and development of a RFID E-Kanban prototype.

\subsection{Problem Statement}

In an effort to increase operational effectiveness, manufactures have started adopting more technologically advanced kanban systems in their production process. One of these systems is the RFID E-Kanban system. However, the use of a new high-tech kanban system does not automatically mean an improved or effective kanban system. Without careful approach and development of how the kanban system supports JIT and lean, this new high-tech kanban system can be minimally effective and potentially add more waste when implemented into the manufacturing process.

Therefore, in order for manufacturers to increase the effectiveness of the RFID E-Kanban system, a RFID E-Kanban methodology with the goal of supporting lean and JIT goals must be established. Once a methodology has been established, the building of a RFID E-Kanban system can be achieved. 


\subsection{Purpose and Scope}

The purpose and scope of this report is to provide companies a detailed system description and framework of a RFID E-Kanban (REK) prototype. A Department of Defense facility will be used as the case study for building a REK prototype. It is important to note that even though the REK

is developed for a specific facility in the case study, companies can still use the approach and general system framework as a blue print to develop their own REK. 


\section{Chapter 2: Background and Literature Review}

\subsection{An Introduction to Lean}

Lean is an operations management philosophy which was developed from Toyota's manufacturing philosophy known as the Toyota Production System (TPS) [14]. The goal of lean is to continually and systematically eliminate all waste in a process in order to achieve a continuous flow of value-added processes to a product [8]. The originator of TPS, Taiichi Ohno, identified seven wastes that did not add value for the customer. The seven wastes are as follows:

- Overproduction - Producing more than the customer ordered.

- Waiting for the next process - Idle time created when material, information, or people are not ready.

- Unnecessary transportation of materials - Movement of product that does not add value.

- Overprocessing - Effort that adds no value from a customer's viewpoint.

- Excess Inventory - More raw material, WIP, or products than the customer needs right now.

- Unnecessary movement by employee - Movement of people that does not add value.

- Producing Defects - Work that contains error, rework, or mistakes.

At the heart of lean is the belief that a process can always be improved. One of the key characteristics of a true lean system is the pursuit to continuously improve [7] [14].

Since the 1970's, manufactures in America have been exposed to the concept of lean. Toyota has since shared its philosophy, principles, and tools to many companies. Concepts and tools such as 
Just-in-Time manufacturing, level work load (heijunka), pull systems, $5 \mathrm{~s}$, and the kanban system are just some of the topics Toyota has shared over the years. Toyota stresses however, that becoming a true lean company is much more than utilizing lean tools. According to Liker in the Toyota Way, some companies have mistaken the adoption of merely the tools of lean to equally mean the adoption of "lean thinking". Liker points out that in order to be a true lean company one must adopt not only the tools of lean but the foundational philosophy of what it means to be lean. Companies who desire to be lean must understand how all the principles and concepts work together in unison toward continuous improvement. Since its inception, the tools and principles of lean have undergone different variations as the concept of lean began to make itself known to other industries. Since the originator of lean was Toyota, the applications and effectiveness of the lean tools are most effective in the automobile industry. "Lean manufacturing" is a phrase to describe a type of lean for manufacturing. Other variations of lean have developed such as "lean Products", "lean Services", "lean Healthcare", "lean Enterprise”, etc. In each of these lean variations, the tools and concepts have been adjusted to adapt to the particular industry condition, but the underlying philosophy and general principles of reducing waste in lean are unchanged.

\subsection{The Kanban System}

One of the most widely used tools in the lean system is the kanban. The word "kanban" in Japanese literally means "signal board". Kanban is best understood in the context of JIT manufacturing [7][3]. JIT manufacturing seeks to produce and deliver the right amount of products at the right time. JIT is described as a "pull system" as opposed to a "push system". The idea of the pull system was inspired when Taiichi Ohno observed how American supermarkets replenished their shelf food items only when there was a low amount of shelf quantity [7]. In a perfect pull system, the creation of products would only be driven by actual customer demand. In 
a manufacturing line, a workstation located upstream would only perform work on a product if there was downstream demand for it. The main purpose of the kanban system is to act as a material flow control mechanism resulting no overproduction or excess inventory [2][3].

The kanban system is setup to help facilitate and manage flow between workstations by using kanban cards to signal material movement coming to and from workstations or suppliers. The original system utilizes two-cards between workstations which includes the withdraw card, and the production card [1]. The original kanban system was designed to be a simple system, allowing operators to signal when they needed materials or when an order from downstream was complete. The kanban system also served another purpose beyond material control. Since kanban cards could be tracked, the system had the ability to reveal problems related to quality, lead time, movement, and other flow managing problems. Managers would then be able to act and remove the waste and thereby follow lean's philosophy of continuous improvement [7].

Since its introduction, many companies have adopted their own version of kanban to support their unique operating business and management philosophy. The advantages of using kanban have been noted for its simplicity, highly visibility, and tight workstation and operation integration. The relatively low cost of implementation and the ease of training operators to use the system have also been mentioned [3]. However, since the kanban system was originally designed for Toyota and the car manufacturing industry, the original kanban system performs optimally under similar industry conditions such as repetitive production sequences that can be buffered without any major demand fluctuations. Four general characteristics have been identified of the original kanban system:

- Use of two communication signals-The production and transportation signal - Pulled production-The production is based upon a pulled based inventory system 
- Decentralized control-Production flow is controlled by employees through each step of the production process by visual signals

- Limited WIP-Limited buffer inventory level at each workstation.

Adaptations and variations to the kanban system have ranged from retaining one to all four characteristics. It is interesting to note however, in terms of implementation, kanban systems which held at least three or more of the original characteristics seem very difficult to implement in today's modern industry [2].

\subsection{Radio Frequency Identification (RFID)}

Radio Frequency Identification (RFID) is a wireless technology system that transmits data via electromagnetic waves for the purpose of automatic identification. A RFID system consists of mainly two components: an integrator and a transponder. An integrator or more commonly known as a reader is used to communicate to the transponder by reading and/or writing. The most commonly known form of the transponder is a RFID tag. In an RFID system, the desired objects to be tracked are outfitted with a RFID tag that can be read by a reader.

RFID was first developed in the 1950's to identify planes. Early uses of RFID began in the aerospace field with the development of radar. Recently, technology advancements have allowed RFID to be used in various applications beyond the aerospace industry and the cost of implementing RFID has steadily become more and more practical. Today, there are three main types of RFID systems: passive, semi-passive, and active. Within the passive RFID category there are also three main types of operating wave frequencies: Lo-RF (LF), Hi-RF (HF), and Ultra-Hi-RF (UHF) [6]. 
The components of a passive RFID tag include a silicon microchip and an antenna. Active and semi-passive tags also have a printed circuit board (PCB) containing their electronic circuits. Tags carry specific information about an item which is read by a reader [4]. This can be very beneficial for any identification and tracking purposes. Passive tags do not contain a power source and are only able to send RF signals by extracting power from the reader's signal. Semipassive tags need a sufficiently clear signal from the reader, but do not need to extract power from the signal since they are equipped with a battery. Active tags are also equipped with a battery, but will constantly send RF signals regardless of the received signal from the reader [6].

Applications for RFID are continuing to be realized (such as warehousing, logistics, healthcare, military, etc). with the most generally applied application being item identification. Unlike barcode, the item does not have to be visibly located in order to scan or read the tag information as long as the item is within the field of operation of the reader. And while RFID does not inherently provide item location information, specifically designed RFID systems such as real time locator systems (RTLS) can provide robust location information from locating an item in a general vicinity to several feet away. Since item identification is a very popular application for RFID, companies and suppliers have been able to more accurately track, manage, and prevent loss of inventory. Both Walmart and the Department of Defense have been two major proponents of RFID, and have encouraged and urged their suppliers to be RFID capable [4].

\subsection{Electronic based Kanbans}

With the advancement of today's information technology, the opportunity to develop sophisticated and automated kanban systems has resulted in the development of the electronic kanban. E-kanban systems are known to incorporate different electronic technologies. Compared to the original kanban, the e-kanban has only one characteristic difference, which is the 
replacement of a physical kanban card with an electronic signal (see above for original kanban characteristics) [2][15].

E-kanban systems have several advantages compared to the original kanban system. First, ekanbans allow greater WIP and inventory visibility throughout the supply chain. An e-kanban system can be setup so that suppliers can track the WIP through computer networks. This can also help in evaluating supplier's performance and accuracy. Second, an electronic signal can be sent and received faster than a physical card. This reduces time, paperwork, and handling of physical kanban cards. Third, it helps improve the speed and quality of operations management. With the ability to send out electronic signals quickly, managers can immediately change or send out the appropriate e-kanban cards to the right stations. This allows for quick adjustment in the production process and is extremely valuable within a stochastic environment when demand is unstable [1][3][5].

Despite the advantages of e-kanban, businesses who adopt new technologies and new knowledge without careful consideration of how it fits into their business strategy may prove useless and even harmful. A known case of this is "The Great Nuclear Fizzle at Old B\&W”. Known for getting the cost per unit as low as possible and the volume as high as possible, $\mathrm{B} \& \mathrm{~W}$ decided to use new technology in producing nuclear pressure vessels. However they did not consider how this new technology would support their business objectives. Unfortunately, this resulted in years of design and process changes without production. This eventually led the company to finally sell their nuclear vessels to competitors to manufacture after failing to find an adequate labor force due to a poor choice of facility location. This all happened because the mangers lacked the understanding of how business strategy relates to operation decisions. New technologies such as e-kanban must be considered within the context of the business strategy [4]. 
Implementations of e-kanban have steadily been increasing since 2000. It has been observed that motor vehicle manufacturers have been earlier adopters of e-kanbans. Toyota in 2000

implemented an e-kanban solution in their France and England factories. In 2006 BMW reported to have installed an e-kanban system.

\subsection{RFID Electronic Kanbans}

One of the most recent technological variations of the e-kanban system is RFID based e-kanbans. Companies who integrate their e-kanban with RFID technology are usually assisted with middleware to connect to their ERP system.

And while e-kanbans are able to send and receive signals electronically, e-kanbans are unable to track unique items in real time. While there has been development of bar code e-kanbans, the barcode based e-kanban is unable to track unique item and their information, only the type of item or stock keeping unit (known as sku). Also with barcode technology, in order to scan an item there needs to be a clear line of sight, a quality not required for RFID technology. An incentive quality of RFID E-Kanbans then, is the ability to provide real time feedback to the operators and managers. This real time information can be used to help with daily decision making regarding WIP tracking and production [16] [17].

In 2006, DailmlerChrysler began a pilot study of an RFID based kanban system in their production plant in Germany. The proof of concept was to identify material flow from storage to the production line via RFID with the goal of increasing process transparency and reducing manual stock inspections. The process starts by an operator handing a production kanban card that contains an RFID chip to a logistics operator. The logistics operator would deliver the production kanban card to the workers in the supermarket. Workers would fill out the kanban 
order and deliver the parts to the designated workstation. The new kanban system enabled DaimlerChrysler to track parts in real time [9]. In 2007, Bosch incorporated RFID technology with their SAP based e-kanban system. RFID tags were placed in kanban cards and RFID readers were strategically setup throughout the facility. Managers would receive an order on the PC and fill out the corresponding RFID kanban card. This allowed the card to be read throughout the production process with its corresponding inventory bin. Bosch estimates that the new RFID EKanban system will save the company more than 1.4 million dollars a year. Bosch reports that since implementing the new RFID system, there have been smaller batch sizes and more frequent customer shipments than before [10].

To build a RFID based kanban system, one framework proposes three levels of integration to achieve a wireless e-kanban system. The first level contains physical and software components which RFID devices are connected to. The second layer is the production management layer that captures and manages the information from the RFID devices. The third layer is the application view that allows the user to view and analyze information regarding material flow and material data [11].

\section{Chapter 3: Methodology}

This section covers the approach of how lean principles were incorporated into the REK design and the examination of facility requirements that would lead to a REK prototype. 


\subsection{Lean Principles Leading to Design}

\subsubsection{Identifying Lean Attributes in the Original Kanban System}

The original kanban system consisted of three major characteristics that supported JIT manufacturing. Any kanban system that is able to retain and/or improve these original can be an effective system.

- Decentralization- The design of the original kanban system empowered each worker along the production line. Since the workers generate and receive the kanban cards which signal when material is made and moved, the workers are essential the ones who are making the decisions of when a product is made. Since the worker is the one who is primarily making these decisions instead of a manager, this gives the worker greater responsibility and accountability. Another positive impact of decentralization is that every worker is now responsible for the quality of the product. No worker is allowed to pass on defective material from their station. This enables the kanban system to have inherent quality inspections all the time while the product is being made.

- Pull System- The original kanban system was created to be a pull system. The advantage of a kanban pull system is the ability to minimize or eliminate excess inventory. Since material can only be produced by actual demand downstream, this reduced the chance of overproduction, a non-value waste. Another advantage with a pull system that minimizes inventory is the opportunity to observe production workflow inefficiency. These inefficiencies are easier to observe when there is low inventory.

- Simplicity and Easability- The operational execution of the original kanban system was simple and easy to use. The workflow of how to handle the kanban cards was not technical and did not require special tools or knowledge. The design of the kanban cards 
was simple and straight forward. Training operators to use the kanban system did not take long. As long as operators knew the different types of the kanban cards and what to do with them, the kanban system was up and running.

\subsubsection{Identify General Lean Principles and Design Concepts}

To support lean, TPS has developed lean principles that help in reducing non-value added waste. Some of these concepts are design related while others directly support the goal of lean. In order to minimize non-value added waste, any new kanban system should take into consideration these lean principles. These principles should be built into the new kanban system in order to improve the operations of JIT manufacturing and lean.

- Continuous Improvement (also known as Kaizen)-This is the process of achieving a perfect system where every step and detail is value added with no waste. Any improvement no matter how small is considered to be part of the continuous improvement process. Every worker in a lean system is expected to strive for perfection and be active in looking for ways to improve the system.

- Mistake Error Proofing (also known as Poke Yoke)-Devices or tools that are used by the operator should be designed in a way that makes it nearly impossible for an operator to make a mistake. When interacting with any type of physical or non-physical tool, the workflow and instructions should be clear and the design should be intuitive.

- Eliminate Waste (also known as Muda)-The seven different types of waste mentioned in the literature and background review (see section 2). The impact of non-value waste in a process lengthens lead time, adds extra movement, and ultimately increases cost to a product. Every attempt should be made to eliminate non-value waste. 
- Quality signaling system (Andon Light)-Solving quality issues right away saves time and money in the long run. When a product flaw is caught by an operator, the operator will activate an andon light signaling that the manager or team leader should inspect the product to determine the appropriate course of action to handling a product flaw or source of the flaw. Solving quality problems right away rather than ignoring them until later saves time and money downsteam.

- Workflow Standardization - Without standardized tasks, there can be no continuous improvement. In lean thinking, standardization is the basis for improvement and quality. In the kanban system, there needs to be s set standard to how to handle the cards and material. It is important to note however, that there needs to be workflow flexibility. The challenge is to find an appropriate balance between providing the operators with workflow guidelines and allowing task creativity. Standards need to allow operators some freedom to innovate in order to improve the process.

\subsubsection{REK Design Objectives}

By taking into consideration both the characteristics of the original kanban system and important lean concepts, the REK design objectives have been determined. The REK design objectives are as follows:

\section{Design a REK prototype that supports continuous improvement}

One of the original advantages of the kanban system was its ability to reveal problems in the production process. In the original system, products were able to be tracked throughout the production process based upon their kanban history record. Many of these records were recorded manually by paper. If anything went wrong during production, records would be reviewed by managers who would then be able to act accordingly to the 
situation. Thus, an important characteristic of the kanban system was its ability to offer opportunities for continuous improvement. Any variation of the kanban system that supports or enhances the process of continuous improvement can be considered consistent with lean design.

\section{Reduce overall non-value added waste in the material flow process}

The original kanban system had inherent potential to eliminate non-value added waste due to its design and implementation. The goal of designing a lean based kanban system to reducing non-value added waste must consider two major factors. (1) The elimination or reduction of waste of the original system by the new system's workflow. (2) The new system's workflow does not add more non-value waste than it eliminates. In summary, the new kanban system's total net of non-value added waste must overall be lower than the previous system that it seeks to replace.

\section{REK prototype must be intuitive and simple to use for the operator}

The simplicity and ease of training operators on the original kanban system is a beneficial advantage to its implementation and execution. Introducing any new system, especially a system with technological components such as a REK prototype, must ensure that the system must not only function properly, but that tasks can easily be executed by the operator. Poke Yoke is a lean concept which refers to mistake or error proofing and can be a valuable concept to consider when developing a new kanban system.

\section{REK prototype control is de-centralized}

Control and movement of materials through the production process will be controlled at each step as is in the original kanban system. This empowers each workstation in a pull system to assume responsibility for their inventory and buffer levels and the quality of the product that their workstation produces. 


\subsection{Identifying Unique Facility Requirements for an RFID Based Kanban Solution}

The Department of Defense facility has a high idle time cost on their WIP inventory, and due to the priority of security, all items must be tracked and managed well. These unique facility requirements lead to a REK prototype solution.

\subsubsection{Product Traceability}

Production facilities that require unique traceability of its products can greatly benefit from an RFID based kanban system. Unlike barcode technology, RFID has the capability of tracking a unique item throughout the supply chain, enabling the company and supply chain partners to have better visibility of its products. Also depending on the RFID kanban implementation, additional information about the individual item can be stored and retrieved electronically. This information may include tracking where the product has been, who has worked on it, and what kanbans have been associated to the item.

The motivation for production facilities interested in traceability may include improving product quality or investigating product source failures. For example, in the semiconductor industry, traceability is used when new batches of wafers are fabricated. In order to increase the success rate of new wafers, experimentation is required for determining which raw materials should be used and by which vendor. Traceability is used for tracking the highest yield wafers made up by certain materials from certain vendors [19]. Semi-conductor companies will then purchase the material from the vendor whose material was related to highest yield wafer batch. For investigating product source failures, the food industry requires traceability anytime when there is a food recall. Traceability will allow the investigation of the food source failures to be 
conducted faster and more effectively throughout the food industry supply chain and with great detail with RFID kanbans [20].

\subsubsection{Automatic Scanning and Location Tracking}

Locating individual items and ensuring correct movement in large production facilities can be achieved with RFID kanbans. While barcode code technology has the ability to identify the item's general location, the operator must have a clear line of sight to scan item and must scan each individual item, which can be a time consuming task. RFID kanbans do not require such a clear line of sight for an item, and is capable reading multiple items as far as the signal can travel. UHF RFID has the maximum read range for current RFID technology and is used in this report since the production facility layout requires long read ranges. This can save the production facility cost and time of trying to locate an individual item.

\subsubsection{High WIP Idle Cost}

While locating individual items in a large facility can be accomplished with just RFID technology, production facilities who handle materials with high idle time cost, need the ability of the kanban system to facilitate clear communication of demand between workstations. Some industries such as the semi-conductor industry have high idle time cost associated with their products [22]. RFID kanbans can ensure that correct movement of materials occur by automatically generating kanban cards when inventory is low or alerting the operator of when a kanban needs to be created. RFID kanbans can help facilitate better communication between workstations on material movement and locate specific items to reduce unnecessary idle time.

\subsection{Determining the Quantity of Kanban Cards}


When building a kanban system, it is necessary to calculate the quantity of kanban cards that the system should have in circulation. There are many different equations available for calculating kanban cards depending on kanban implementation and unique production situation. Shown below is an industry standard general equation from SAP ERP to determine the number of kanban cards [17]:

$$
K=\left[\frac{(R T \times A C)}{C O N T}\right] \times[S F+C]
$$

Where:

$\mathrm{K}=$ numbers of Kanban

$\mathrm{CONT}=$ contents per Kanban

$\mathrm{RT}=$ replenishment lead time per Kanban

$\mathrm{AC}=$ average consumption per time

$\mathrm{SF}=$ safety factor (default 1$)$

$\mathrm{C}=$ constant (default 0$)$

The number of kanban cards for the REK prototype is calculated in section 5.5

\section{Chapter 4: The General REK Model Overview}

This section provides an overview of the design of the REK prototype including the operator workflow and software architectural design. The prototype design was developed for two workstations that would be in sequence to one another in a production line but this design can be extended to include more sequential processes.

\subsection{General Model Overview}


For two workstations, the REK prototype is divided into two major processes: the withdraw and the production kanban process (shown in Figure 1 next page). In each process there are two stages: an initial stage and a final stage. Once a final stage in a process is complete, the next process's initial stage can begin. The model begins at the initial stage in the production kanban process when workstation[i+1] needs material from workstation[i]. Once workstation[i] receives the production kanban, workstation[i] will deliver the ordered materials to workstation[i+1] in the withdraw kanban process. For detailed explanation for each process see sections 4.2 and 4.3.

\subsection{Production Kanban Process Workflow}

The purpose of the production process is to replenish material by signaling to the preceding process which goods/materials need to be produced and where they are to be delivered. The production process is divided into two stages beginning in workstation [i+1] and ending in workstation [i]. The beginning production stage starts when workstation $[i+1]$ depletes its inventory (or inventory buffer level). When this occurs, a production kanban is generated, signaling a request for more material from workstation [i]. In addition to signaling a request for 


\section{General REK Prototype Overview}

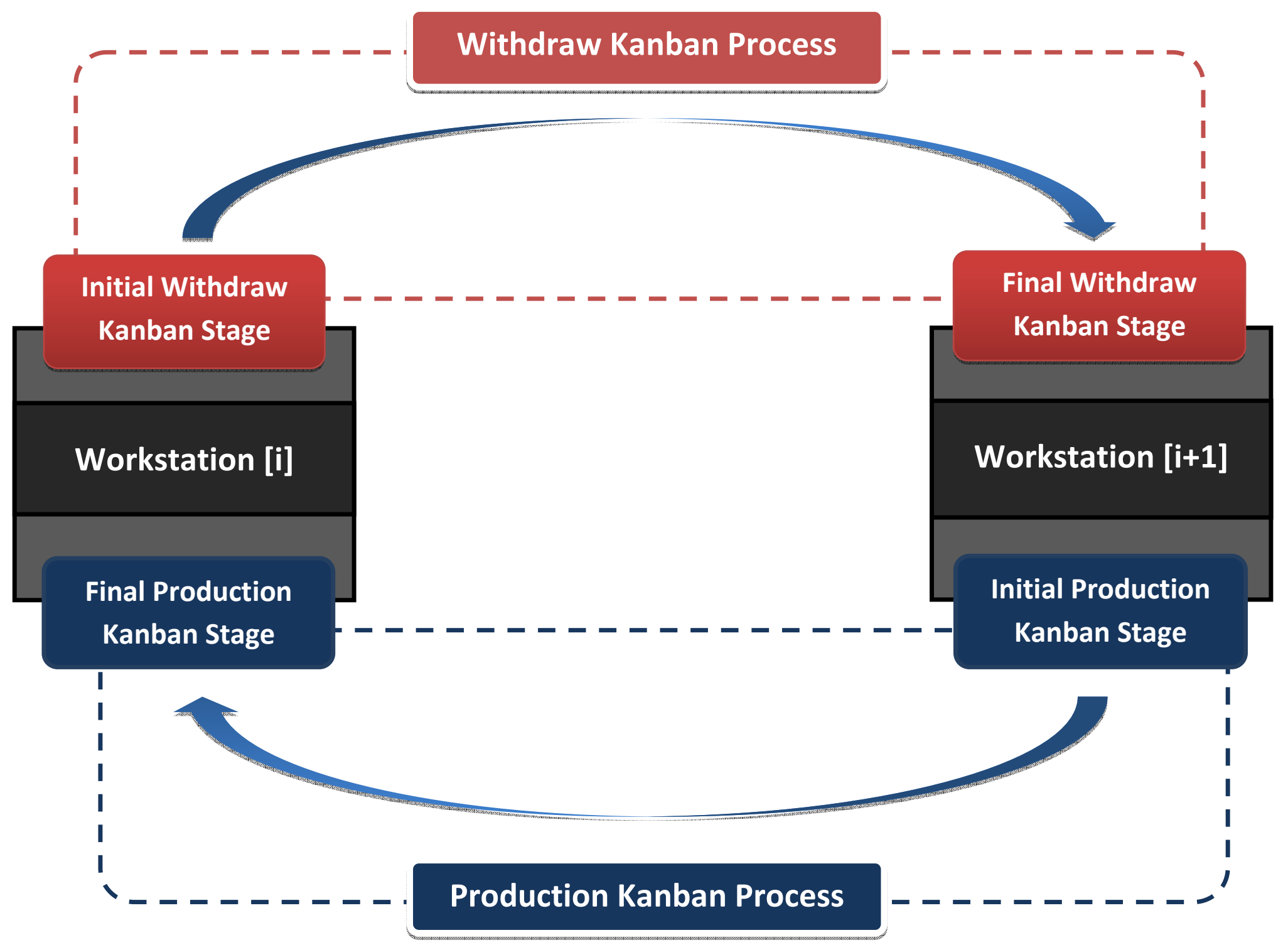


more material, any empty containers (or pallets, bins, etc.) brought from process[i] will be transported back to workstation[i]. (These containers were initially transported from workstation [i] to workstation $[i+1]$ during the withdraw process.) These outgoing containers will be scanned by the RFID system automatically to ensure an accurate update of their status. When empty containers arrive at process[i], the RFID system will then scan and confirm their arrival. In the final production stage, once workstation [i] acknowledges the request of the production kanban, production of goods can begin. When the production of goods is complete, workstation [i] can begin the withdraw process and the production kanban will be updated to indicate it has been fulfilled. See Appendix A for a graphical view of the initial and final stage production kanban workflow.

\subsubsection{Production Kanban Process Framework}

This section presents the conceptual framework of the relationships between the different physical and non-physical levels in the production kanban process. (This conceptual framework was inspired by the OSI model [21].) This framework is a high level planning view used to describe the levels in their contexts and can also be used as a technology road map for future improvements. (See Figure 2 on the next page.) The description of each level as follows:

Operator Workflow Level - This level encompasses the workflow sequences that need to be followed to successfully generate a production kanban. Both initial and final stages are shown in relation to the sequence of each other and the relationship with the RFID level (the level above). The relationship with the RFID level and the operator workflow is a physical interaction involving the RFID reader to scan RFID tags when the operator returns a container, begins 


\section{Production Kanban Process Framework}

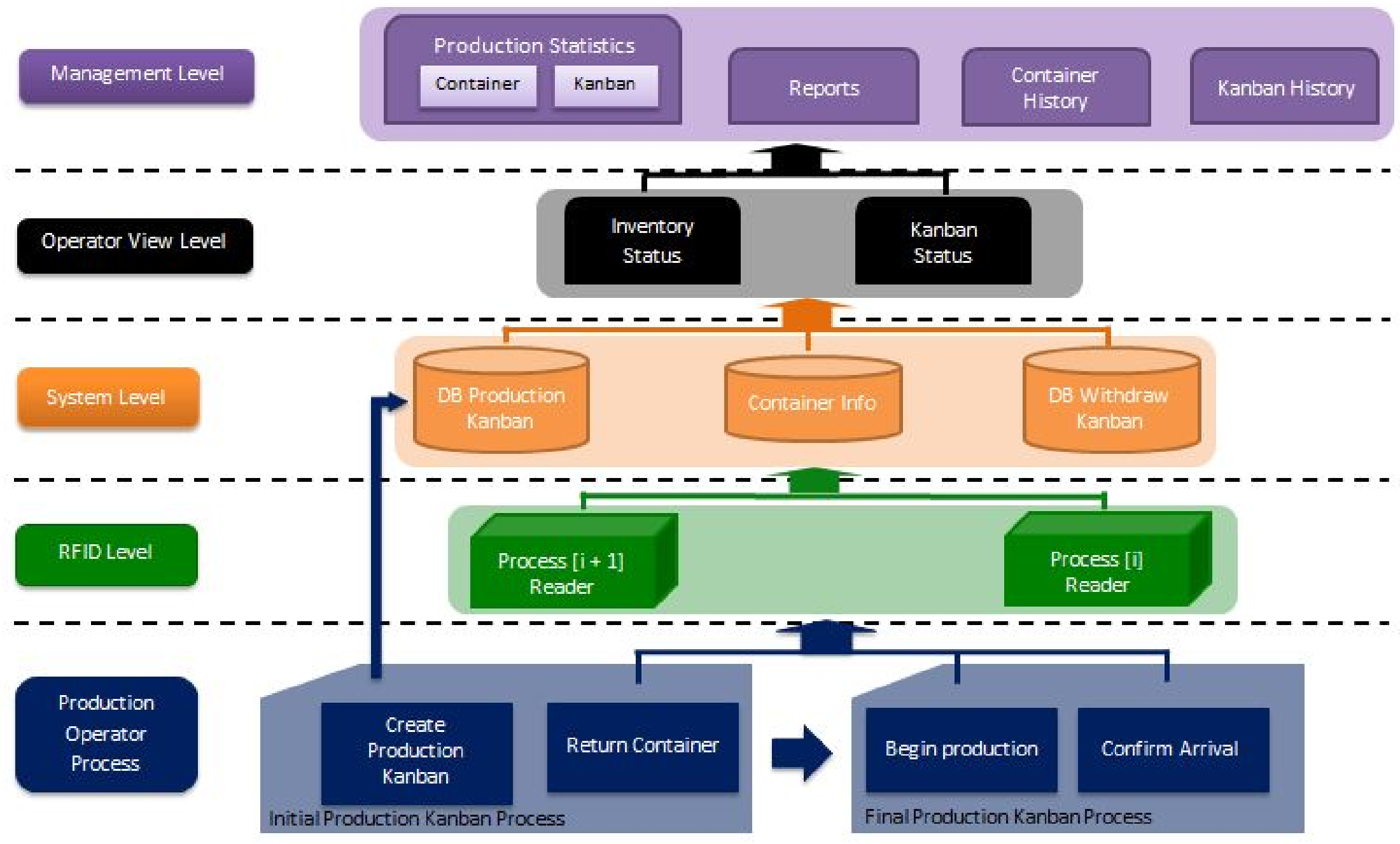


production, or confirms the arrival of the container. It is important to note however, that the action of creating a production kanban card does not interact with the RFID level but at the system level in the production kanban database. This is because the information needed to generate a production kanban is stored in the production kanban database without needing to scan a RFID tag.

RFID Level- Each workstation is equipped with an RFID reader and antennas which can scan and read RFID tags that come within the readable range. Any relevant tag information is scanned and sent to the system level where tag information can be stored, queried, and analyzed. At the RFID level, the readers can be programmed to set antenna settings and advance read settings.

System Level-There is three main components in the system level: the production kanban database, the withdraw kanban database, and container information. The production kanban database holds all the active, canceled, or closed production kanbans. Each production kanban has timestamps when the card was created and closed. The withdraw kanban database holds all the holds all the active, canceled, or closed withdraw kanbans. Just like the production kanban, the withdraw kanban contains timestamps when the card was created and closed. The inventory information component holds any relevant information regarding the information on the inventory such as its current location and item information. The system level is accessed by the operator view level, where the system level information can be queried and viewed.

Operator View Level-This level is for the operator who is currently working in the REK prototype. There are two components in the operator view level: the current status of the container and the production kanban. This information would be helpful to the operator in completing their assigned tasks in the production kanban process. 
Management Level- Information about the inventory and kanbans can be analyzed and assessed for future reference and improvement operations. At this level, the manager can generate reports and view statistical information regarding the performance of the system. This level provides all the tools necessary to manage and analyze the system.

\subsection{Withdraw Kanban Process Workflow}

The purpose of the withdraw process is to ensure correct movement of material from workstation [i] to workstation $[i+1]$. The withdraw process is divided into two stages beginning in workstation [i] and ending in workstation $[i+1]$. The withdraw kanban process only begins when there is a demand upstream (workstation $[i+1]$ ) which is communicated via the production kanban. In the beginning withdraw stage, once goods are ready to be transferred to workstation [i+1], a withdraw kanban is created. The material is then scanned and confirmed by the RFID system to be transferred. The RFID system will then upload the proper status update depending if the inventory is waiting to be withdrawn or is currently in transit. Once the goods have been delivered to workstation $[i+1]$, the final withdraw stage begins. In the final withdraw stage, the transfer of goods is scanned by the RFID system and confirmed by the operator. The RFID system will then update the status of the withdraw kanban to "received". The withdraw kanban is then fulfilled and closed by the operator. See Appendix B for a graphical view of the initial and final stage of the withdraw kanban workflow.

\subsubsection{Withdraw Kanban Process Framework}

This section presents the conceptual framework of the relationships between the different physical and non-physical levels in the withdraw kanban process. (See Figure 3 next page.) This framework is a high level planning view used to describe the levels in their contexts and can also 


\section{Withdraw Kanban Process Framework}

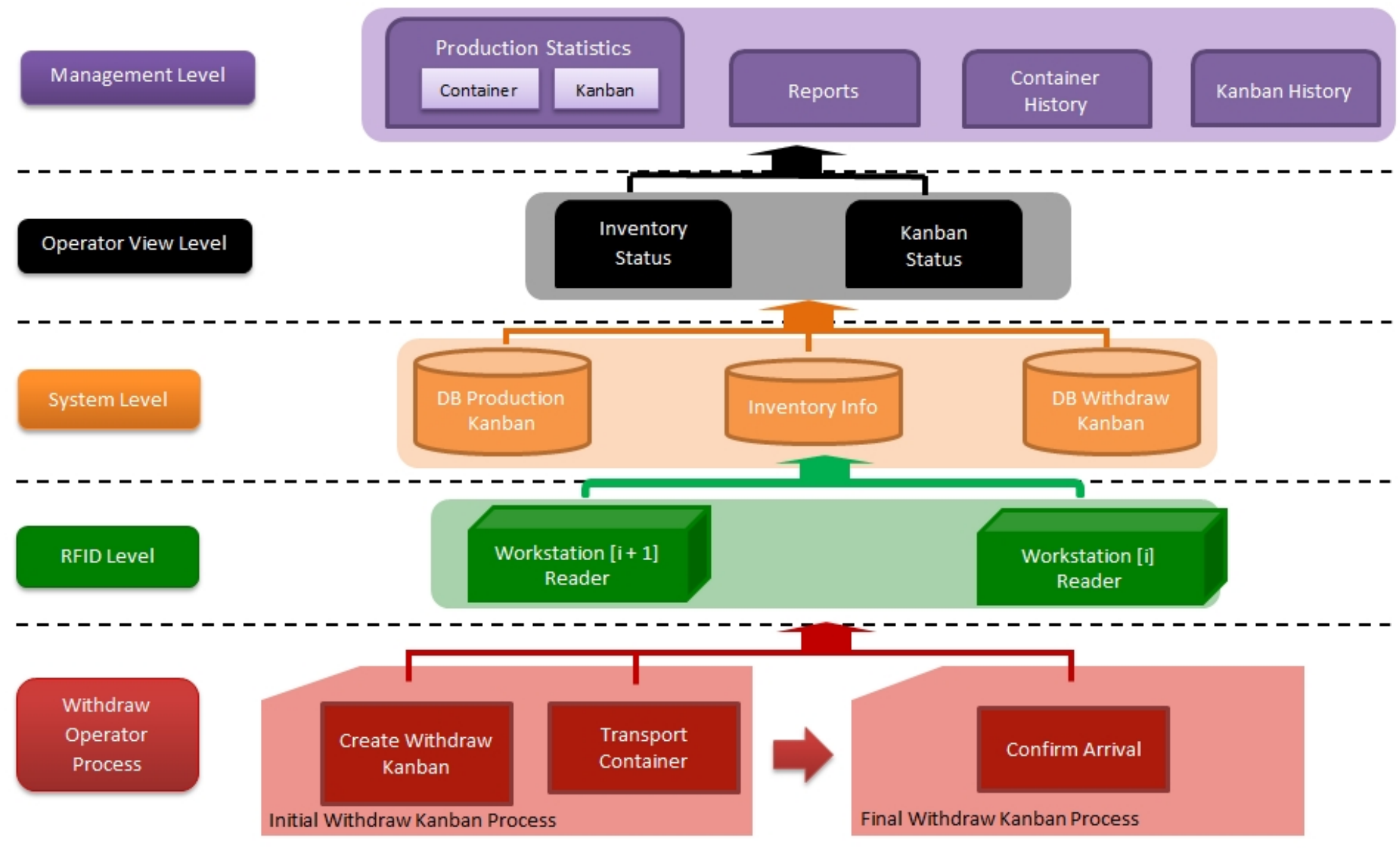

Figure 3-Withdraw Kanban Process Framework 
be used as a technology road map for future improvements. (Note: The presentation conceptual framework was inspired by the OSI model [21].) The description of each level as follows:

Operator Workflow Level - This level encompasses the workflow sequences that need to be followed to successfully generate a withdraw kanban. (For a detailed explanation of each individual workflow refer to section 4.3.1.) Both initial and final stages are shown in relation to the sequence of each other and the relationship with the RFID level (the level above). The relationship with the RFID level and the operator workflow is a physical interaction with the operator using the RFID reader to scan RFID tags when creating a withdraw kanban, transporting goods, and confirming the arrival of the goods.

RFID Level (same as production kanban framework) - Each workstation is equipped with an RFID reader and antennas which can scan and read RFID tags that come within the readable range. Any relevant tag information is scanned and sent to the system level where tag information can be stored, queried, and analyzed. At the RFID level, the readers can be programmed to set antenna settings and advance read settings.

System Level (same as production kanban framework) - There is three main components in the system level: the production kanban database, the withdraw kanban database, and container information. The production kanban database holds all the active, canceled, or closed production kanbans. Each production kanban has timestamps when the card was created and closed. The withdraw kanban database holds all the active, canceled, or closed withdraw kanbans. Just like the production kanban, the withdraw kanban contains timestamps when the card was created and closed. The inventory information component holds any relevant information regarding the information on the inventory such as its current location and item information. The system level 
is accessed by the operator view level, where the system level information can be queried and viewed.

Operator View Level (same as production kanban framework) - This level is for the operator who is currently working in the REK prototype. There are two components in the operator view level: the current status of the container and the production kanban. This information would be helpful to the operator in completing their assigned tasks in the production kanban process.

Management Level (same as production kanban framework) - Information about the inventory and kanbans can be analyzed and assessed for future reference and improvement operations. At this level, the manager can generate reports and view statistical information regarding the performance of the system. This level provides all the tools necessary to manage and analyze the system. 


\section{Chapter 5: Results and Case Study}

This section reports the results of building a RFID E-Kanban prototype for a Department of Defense facility. The REK prototype will be designed for two workstations utilizing chemical containers. In a process of developing a REK prototype for the DoD, adaptations from the general REK model were considered and implemented to meet system requirements.

\subsection{Background on Department of Defense Facility Case Study}

The Department of Defense (DoD) facility in this case study manufactures microchips that support military systems and vehicles in the United States military. This facility interacts with military program managers as well as military contractors related to microelectronic technology. During the fabrication process of producing microchips, chemicals are applied onto the microchips for protection and functionality. When not in use, the chemicals are stored in a chemical storage house away from the location where the chemicals are applied. The location where the chemicals are applied to the microchips in the DoD facility is known as the Foundry. These chemicals have strict environmental guidelines regarding how they are to be used and disposed. The development for the REK prototype will be for the facilitation of the transport and demand of chemicals from the Storage to the Foundry area. The REK prototype will also add new chemical containers into the kanban system. Figure 4 on page 30 depicts the relationship between the foundry and the storage area in the kanban system.

\subsection{Case Study Motivation}

Since the Department of Defense facility is involved in the fabrication of microchips, the importance of traceability as mentioned in Section 3.2.1 is considered a high priority to the facility's production process with additional emphasis on operator accountability for product 
movement. The DoD facility also needs an effective way for managing the flow of their WIP due to high idle time cost. Since the security of the chemical container is of high priority, as requested from the facility, the REK prototype will not automatically generate kanbans. Every chemical container attached to a kanban will require manual operator authorization. While this adds an additional step in the creating a kanban, the Department of Defense deems it a necessary step for security reasons.

\subsection{Consideration of Lean Challenges Involving Chemical Inventory Tracking}

\section{In The Department of Defense}

Since the September 11, 2001 terrorist attacks in the United States, there has been a concern for the protection and tracking of chemical assets worldwide [12]. Inventory tracking of chemicals is now considered to be a security priority in the DoD. Manual inventory inspections of the location of chemicals and examination of their contents however, are considered a non-value waste in a lean system. Furthermore, in manual inspections, mistakes may be made by the inspector which results in non-value waste. The REK prototype can help reduce inventory mistakes by utilizing RFID technology. Other non-value waste can also potentially enter the inventory system if the inspection and documentation process is paper based. The electronic component the REK can eliminate the need for paper documentation and can alert the operator to incomplete inventory entries. 


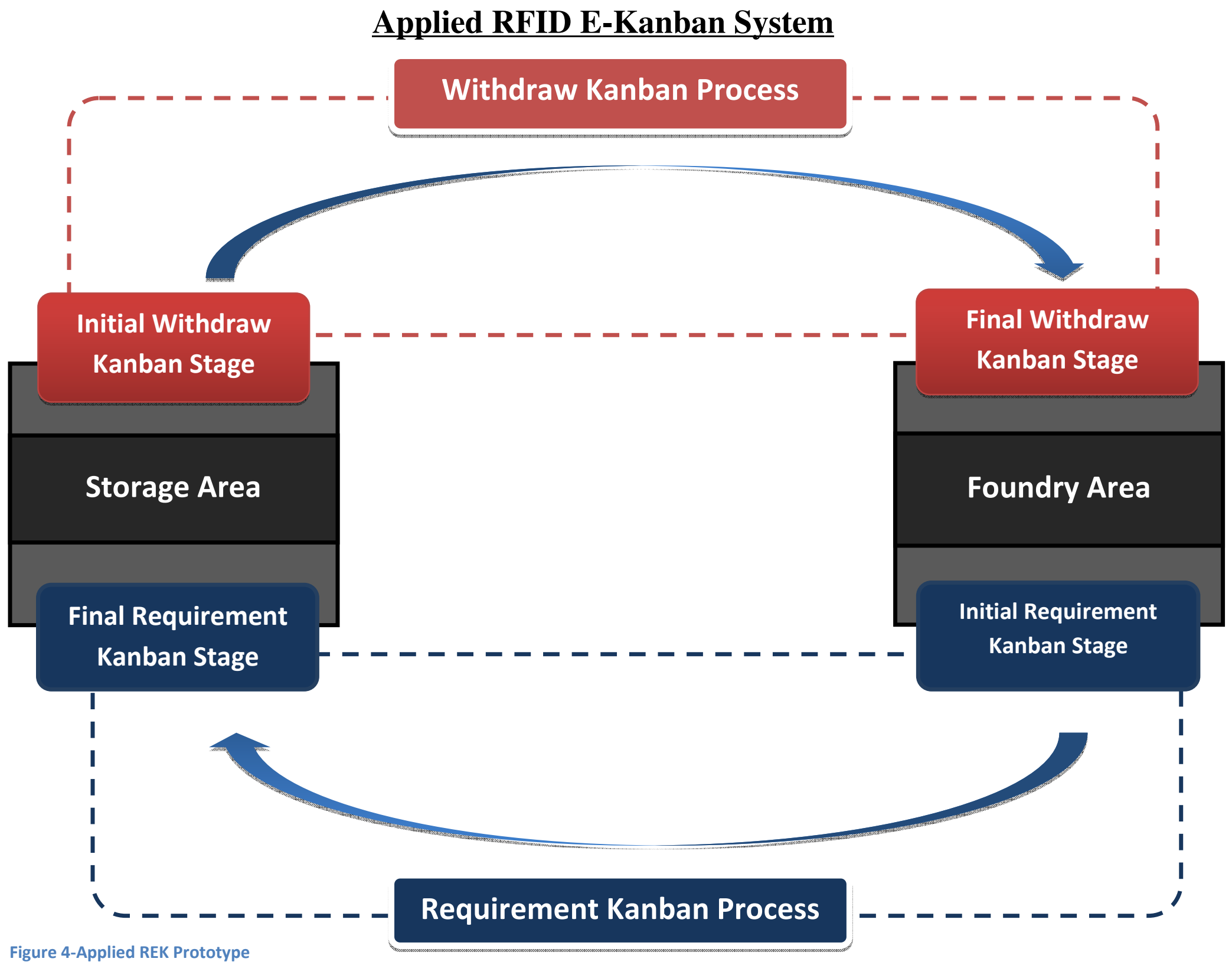




\subsection{Physical Considerations for RFID Configuration and Setup}

\subsubsection{Chemical Movement Between the Storage and Foundry Area}

When the foundry needs a chemical container, an operator from the storage house will transport a chemical container to the foundry. The physical boundary between the storage house and the foundry area is separated by two doors and a long hallway. The current dimensions of a chemical container are $1.5 \times 1 \times 1 \mathrm{ft}$. For a graphical view, Figure 5 below shows the relative locations between the storage and foundry area. (Figure 5 purposely omits drawing dimension and facility layout details due to facility security concerns.)

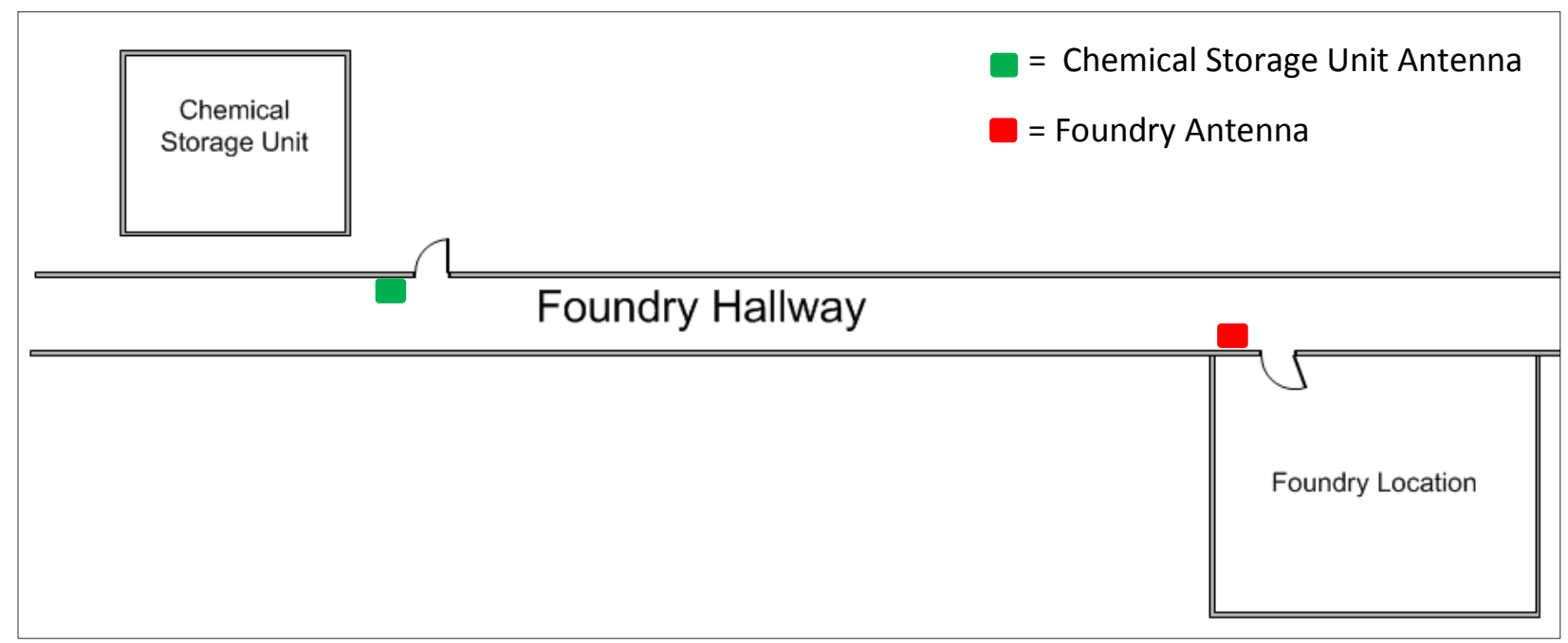

Figure 5 - Layout of Chemical Storage Unit and Foundry Area

\subsubsection{RFID System Setup}

Since the chemical storage unit and the foundry location is separated by two doors, a RFID antenna will be installed by the two doors to track when a chemical container has left or arrived on location. The distance between the two areas is large enough so that the antenna signals will not overlap. The RFID antennas will scan automatically the chemical container when the chemical container reaches the each locations respective door. Therefore, the RFID component 
of the REK prototype requires a setup of one reader and two antennas to capture movement between the two locations. The chemical containers are able to be scanned with passive tags by the reader and do not require self-generated power as a semi-passive or active tag would as it would more expensive.

\subsection{Kanban Card Calculation}

The total number of kanbans in circulation was calculated to be five kanban cards. The calculation of determining the quantity of kanban cards that should be in circulation are as follows (refer to Section 3.2.1 for kanban equation):

$$
5 \approx\left[\frac{(3 \times 1)}{1}\right] \times[1.645+0]
$$

Where the variables were determined as:

$\mathrm{RT}=3$ weeks per cotnainer

$\mathrm{AC}=1$ container peer week

Cont $=1$ container per kanban card

Constant $=0$ (default)

The safety factor was calculated to a $95 \%$ statistical probability for chemical inventory levels which yields a safety factor of 1.645

\subsection{Adapting the REK General Model to the DoD facility}


Anytime when a kanban system is developed for a certain company or facility, adjustments and identification of important kanban system components is needed. This section covers the adjustments and identification the components of the REK prototype needed to make from the general model. Since the material/inventory of interest was the chemical container (see section 5.2.1), the name of the applied RFID E-Kanban prototype for the DoD facility was chosen to be the ChemTRACE prototype.

\subsubsection{Changes in terminology}

In order to not confuse operators, since the storage area does not actually "produce" a product, the production kanban name was changed to "requirement" kanban, since the microchip fabrication process in the Foundry area requires chemical treatment. Figure 4 on page 30 reflects this terminology change. However, the original purpose and function of the production kanban remains the same.

\subsubsection{Adaptations in Model Framework}

The DoD facility currently has in place a procurement system that oversees all production and inventory activity. This procurement system is outfitted with all the functionality that is expected in the management level system framework. Therefore, the information in the ChemTRACE prototype would feed into the procurement system upon implementation. Therefore, since the management level already exists with the procurement system, a management report system built into ChemTRACE was not necessary.

\subsubsection{Identifying Material of Interest}


The unit of material to be "produced" and transported back and forth from the storage location to the foundry will be the chemical container. Since the foundry normally deals with low quantities of chemical containers at a time, each production kanban is a signal for one chemical container. Each chemical container will be outfitted with a passive UHF tag so that the RFID reader can read the tag's signature.

\subsubsection{Identifying workstations}

It has been identified that workstation[i] is the storage location and workstation[i+1] is the foundry location (see Figure 4 on page 30). The ChemTRACE prototype will be developed for these two workstations.

\subsubsection{Added Functionality: Recording Container History}

Upon request of the foundry supervisor, the ChemTRACE prototype will capture the container location history as it moves between the storage and foundry area. This request can be viewed in Appendix C. This ability to track the location history of the container has important implications for microchip process traceability and operator accountability.

\subsubsection{The Requirement Kanban}

The information on the requirement kanban will include what type of material will be ordered, who ordered it, where should it be delivered, and by what date. Only the foundry operator will be able to generate this kanban card. See section 5.7.11 for the user interface of generating a requirement kanban.

\subsubsection{The Withdraw Kanban}


The information on the withdraw kanban will include what type of material is to be transported, who authorized it, where it should be delivered and by what date. Only the storage operator will be able to generate this kanban card. See section 5.7.15 for the user interface of generating a withdraw kanban.

\subsection{Software Components}

The ChemTRACE software was completely programmed by the author (see Appendix D for selected software code).

\subsubsection{Programming Language C\# .NET}

The ChemTRACE prototype was programmed in C\# .NET as recommended by the DoD facility. C\# .NET is an object-oriented programming language developed by Microsoft. The integrated development environment that ChemTRACE was developed in was Microsoft Visual C\# Express 2010.

\subsubsection{Database}

The database component in ChemTRACE is Microsoft SQL 2008 R2. Microsoft SQL 2008 R2 is a relational database management system developed by Microsoft. In the ChemTRACE prototype, four tables were developed. The description of the four tables is as follows:

\section{$\underline{\text { Withdraw Kanban Table }}$}

This table holds information for the withdraw kanban. The primary key for this table is the Withdraw Kanban Identification number. This table has a foreign key relationship with the production kanban table (PK_ID) and the Container Information table (Container_ID). 
Table 1-Withdraw Kanban Table

\begin{tabular}{|cl|}
\hline Column Name & \multicolumn{1}{|c|}{ Data Type } \\
\hline WK_ID (Primary Key) & Nvarchar (50) \\
\hline PK_ID & Nvarchar (50) \\
\hline Container_ID & Nvarchar (50) \\
\hline Created & Date \\
\hline Status & Nvarchar (50) \\
\hline Location & Nvarchar (50) \\
\hline Operator_Name & Nvarchar (50) \\
\hline Due_Date & Date \\
\hline Material & Nvarchar (50) \\
\hline Closed & Date \\
\hline
\end{tabular}

- WK_ID - The identification number of the withdraw kanban card.

- PK_ID - The identification number of the associated production kanban card.

- Container_ID - the identification number of the associated container with the withdraw kanban card

- Created -The date and time that this kanban was created.

- Status -The status of this kanban card.

- Location -The location of where the material is to be delivered.

- Operator_Name - The operator that created this kanban card

- Due_Date - The date that the material is supposed to be delivered.

- Material - The type of material/inventory that is requested.

- Closed - The date and time when this kanban card was fulfilled. 


\section{Production Kanban Table}

This table holds information for the production (requirement) kanban. The primary key for this table is the Production Kanban Identification number.

\begin{tabular}{|c|c|}
\hline Column Name & Data Type \\
\hline PK_ID (Primary Key) & Nvarchar (50) \\
\hline Created & Date \\
\hline Status & Nvarchar (50) \\
\hline Location & Nvarchar (50) \\
\hline Operator_Name & Nvarchar (50) \\
\hline Due_Date & Date \\
\hline Material & Nvarchar (50) \\
\hline Closed & Date \\
\hline
\end{tabular}

- PK_ID -This is the identification number of the production (requirement) kanban card.

- Created -The date and time that this kanban was created.

- Status - The status of this kanban card.

- Location -The location of where the material is to be delivered.

- Operator_Name - The operator that created this kanban card

- Due_Date - The date that the material is supposed to be delivered.

- Material - The type of material/inventory that is requested.

- Closed - The date that this kanban card was closed. 


\section{Container Information Table}

This table holds information for the container item. The primary key for this table is the Container Identification number. This table has a foreign key relationship with the Container History Table (Container_ID).

\begin{tabular}{|} 
Table 3-Container Information Table \\
\hline Column Name & Data Type \\
\hline $\begin{array}{c}\text { Container_ID (Primary } \\
\text { Key) }\end{array}$ & Nvarchar (50) \\
\hline Created & Date \\
\hline Location & Nvarchar (50) \\
\hline Description & Nvarchar (MAX) \\
\hline RFID_Tag & NvarChar \\
\hline Material & Nvarchar(50) \\
\hline
\end{tabular}

- Container_ID - The identification number of the container.

- Created -The date and time that the container was entered into the database.

- Location -The current location of the container.

- Description - Information entered by in the operator that is relevant to the container.

- RFID_Tag - The Radio Frequency Identification number of the tag that is attached to the container.

- Material - What type of inventory/material this container holds.

Container History Table 
This table holds information of the history of the container. The primary key for this table is an auto generated number.

Table 4-Container History Table

\begin{tabular}{|cc|}
\hline Column Name & Data Type \\
\hline ID (Primary Key) & Int (autonumber) \\
\hline Container_ID & Nvarchar (50) \\
\hline Location & Nvarchar(50) \\
\hline Time & datetime \\
\hline
\end{tabular}

- $\quad$ ID - This is an auto-generated identification number.

- Container_ID - The identification number of the container.

- Location -The location that the container was in

- Time - The time when the container entered into the location

\subsection{Hardware Components}

\subsubsection{RFID Hardware}

The ChemTRACE prototype was programmed to be connected with a Sirit Reader 510 with two antennas. If the user wants to use a different type of RFID reader, the user must reprogram some of the code in the software for ChemTRACE to talk to the new reader.

For setting up the Sirit 510 reader, please consult Sirit's 510 user guide for proper installation and system setup. Depending how the reader is connected to a computer (either directly or through network), the setup may differ for each location.

\subsection{Hardware and Software Development Location}


The ChemTRACE prototype was developed in Cal Poly's Laboratory for Global Automatic Identification Technologies (PolyGAIT) [12]. PolyGAIT is located in San Luis Obispo, CA.

\subsection{ChemTRACE prototype Graphical User Interface (GUI) Description}

This section provides an overview of the description and functionality of the GUI throughout the ChemTRACE prototype.

\subsubsection{Main Form Screen}

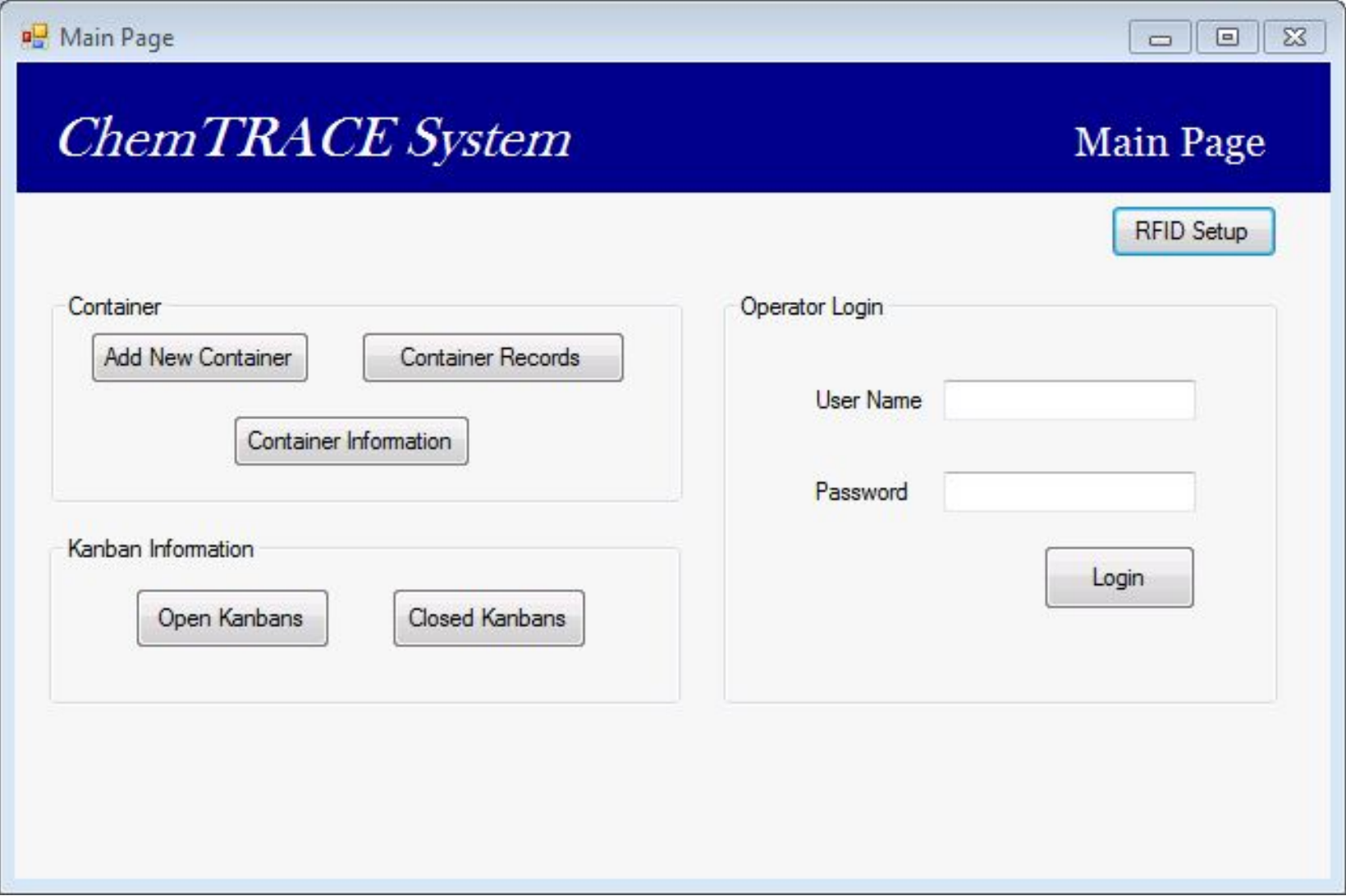

Figure 6-Main Form Screen 


\section{How To Access The Form:}

This is the form that will appear once the software has been opened.

\section{Main Form Screen Description}

The Main Form (see above Figure 6) is the first page and starting point in the software. On the Main Screen, accesses to other forms are grouped by categorical tasks. This is done to help user navigate in a simple and intuitive way. The operator can access any of the displayed forms by simply clicking once on the desired button. The main screen will remain open and will not close automatically when the operator opens a new form.

On this page the user can look up container information or kanban information without logging in which is ideal if an operator or manager wants to quickly bring up the status of a certain container or a status of a kanban card.

Every operator working in the REK prototype will be given a user name and password for their appropriate workstation. Once logged in, the software will display the appropriate option of forms that the workstation is allowed to access. In this case study we have two types of operators, a foundry operator and a storage operator. 


\subsubsection{New Container Form}

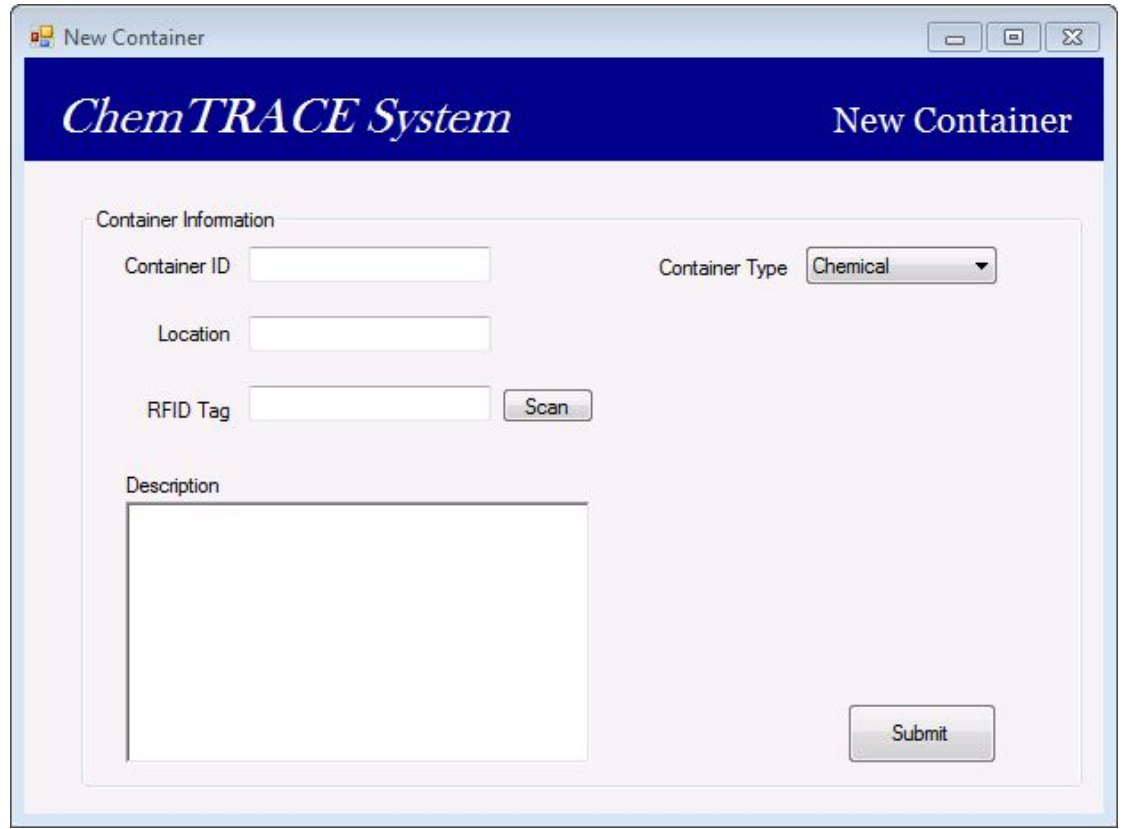

Figure 7-New Container Form

How To Access The Form:

The New Container Form can be accessed from the Main Screen Form by clicking the "Add New Container" button.

\section{$\underline{\text { New Container Form Screen Description }}$}

In the New Container Form (see Figure 7 on page 41) the user can add a new chemical container into the system. All fields on the form must be filled out in order for the new container to be successful submitted into the system. The following descriptions of each field are as follows.

Field Descriptions below:

- Container ID - The unique identification number of the container that is known by the organization. This identification number would be equivalent to a part number in a 
manufacturing company. The identification number can be a combination of numbers and letters.

- Location - The current location of the container. Usually the storage facility of where the container is initially kept.

- RFID Tag - The RFID tag identification number that will be correlated to the container. The user can scan in a RFID Tag using the proper antenna station where new containers are scanned in. The description of a scan form is shown in section 5.4.3

- Container Type- The content that the container holds. For this case study, the only option available will be of a chemical container. This can updated later for future implementations if needed.

Once the user has completed filling out all the fields the user will click "submit" to insert the new information into the database. If the user did not fill out all the fields, a message box will appear to inform the user to fill out all the fields.

\subsubsection{Scan Tag Form}

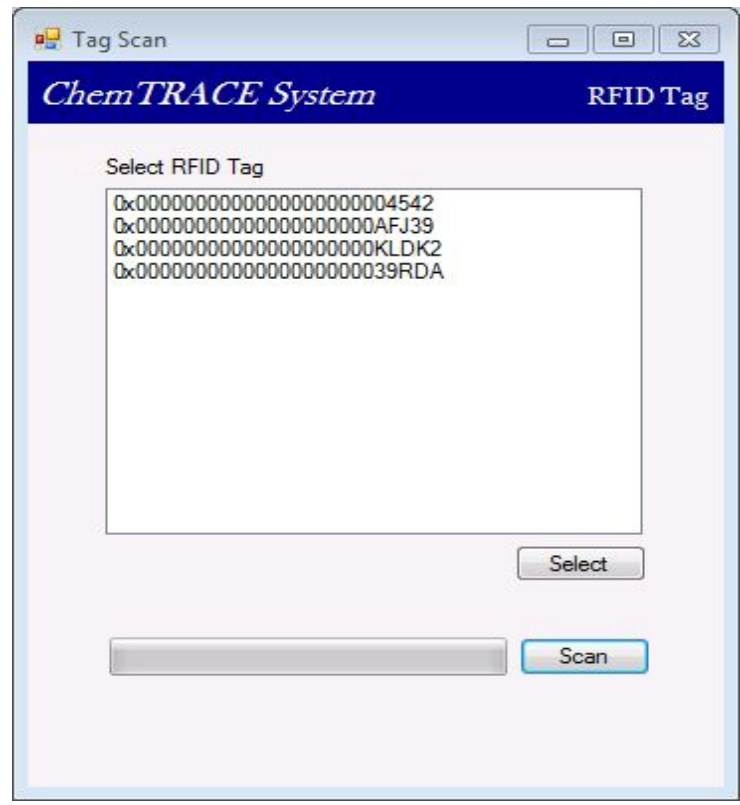




\section{How To Access The Form:}

Click the "Scan" button that appears on any form.

\section{$\underline{\text { Tag Scan Form Screen Description }}$}

The Tag Scan Form (see Figure 8 above) allows the user to scan any RFID tag within the readable range of the designated antenna station. This task can be done by clicking the button "scan". There will be a 1 scan time for the reader to scan. Once the scan is done, any scanned tags will appear in the list box screen. The user can then select any tag and click "select" to have the RFID tag inputted in the appropriate field.

\section{Forms that currently use the Scan Tag Form:}

- New Container Form-Use the Scan Tag Form to scan the RFID tag that will be associated with the new container

- Create Withdraw Kanban Form - Use the Scan Tag Form to associate the container with the withdraw kanban card. 


\subsubsection{Container Records Form}
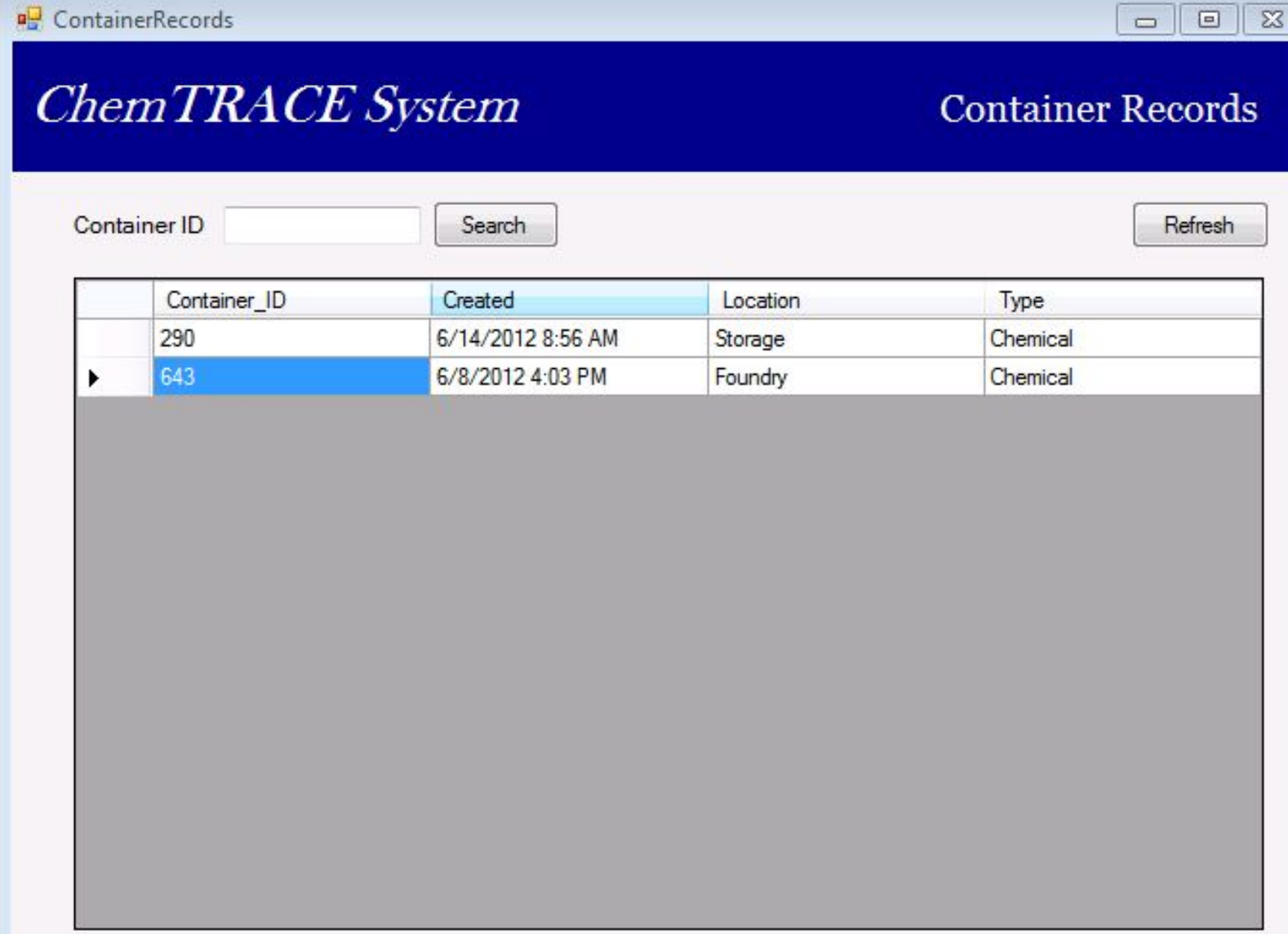

Figure 9-Container Records Form

How To Access The Form:

From the Main Screen click "Container Records".

\section{Container Records Form Description}

Container Records (see Figure 9 on page 44) allow the operator to view general container information in a listed grid view format. The form can also search for a container or group of containers depending on the search Container ID. The search capability on the grid view gives the user a way to view a particular container or group of containers. The user can also double 
click on Container ID cell to open the form Container Information, where more detailed information about the specific container is available.

\subsubsection{Container Information Form}

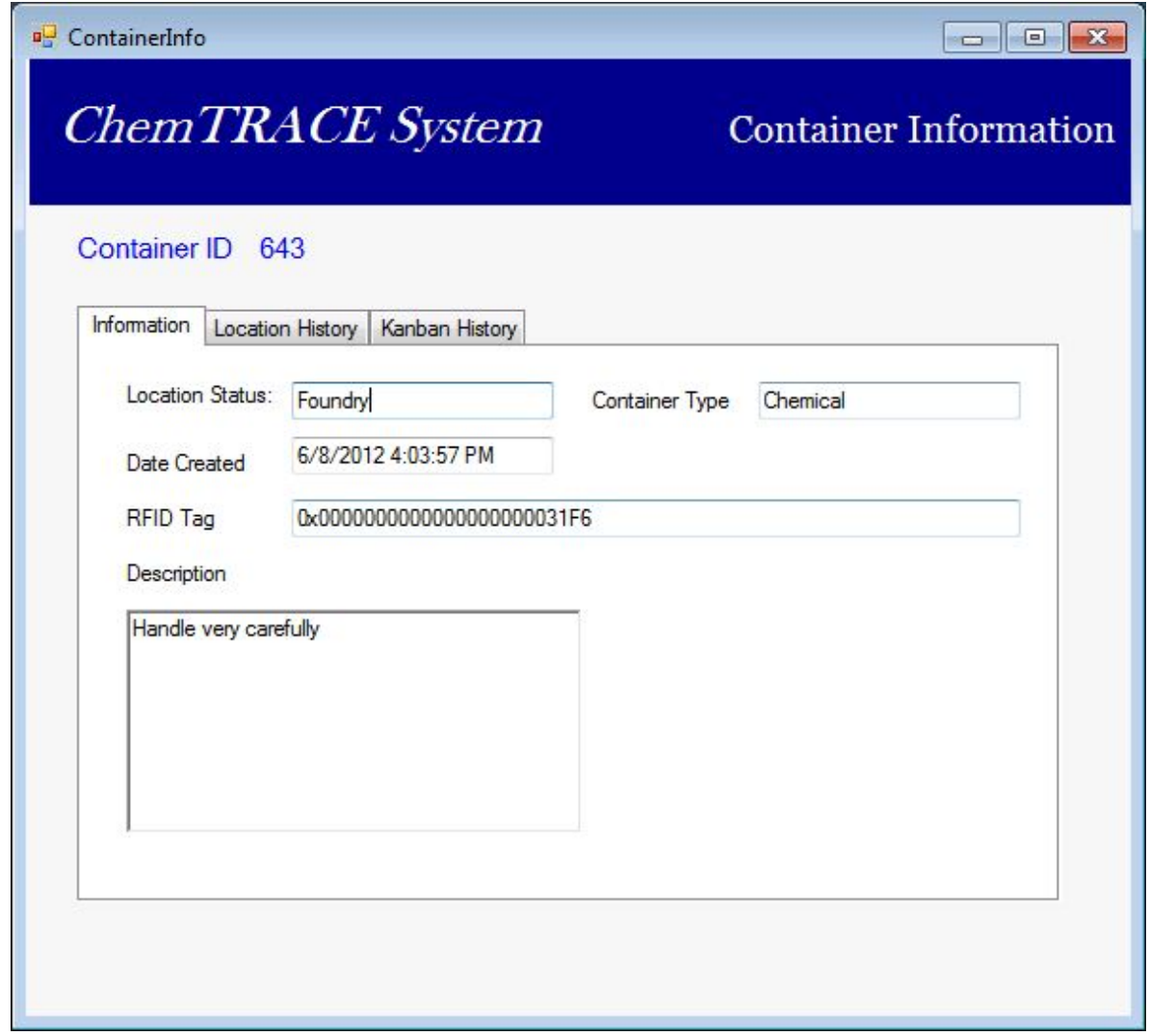

Figure 10-Container Information Form

\section{How To Access The Form:}

You can access the form 2 ways:

1. From the Main page click "Container Information"

2. Double-click on a cell in Container Records to display that specific container information 


\section{Container Information Form Description}

In Container Information (see Figure 10 above), the user can view any related container information. The information is divided into three tabs: information, location history (see Figure 11 below), and kanban history (see Figure 12 on page 47). In the container information tab, general container information is displayed for the user. In the location history tab, all the location readers that have read the container's RFID will displayed with location and time. In the kanban history tab, all the withdraw kanbans and their associated requirement kanbans are displayed. A user can double-click on any of the cells in the withdraw kanban tab to open up the Withdraw Kanban Card form.

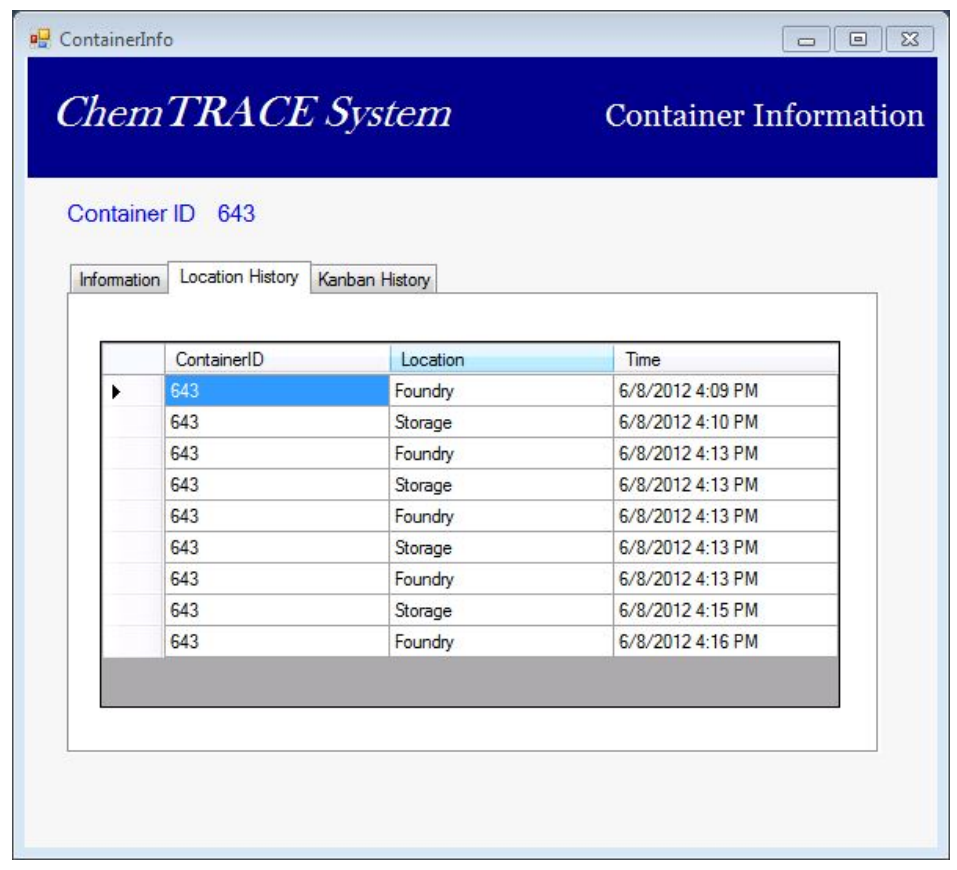

Figure 11 Location History 


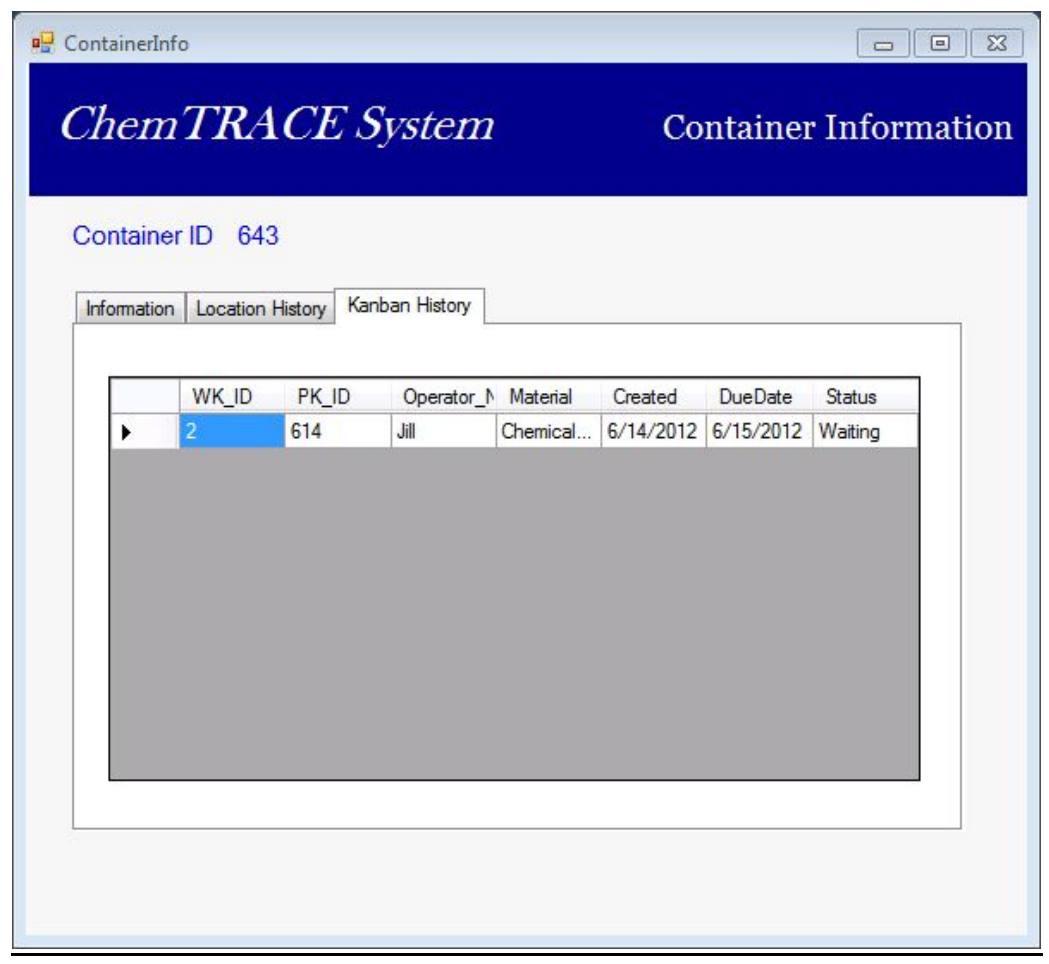

Figure 12- Kanban History

\subsubsection{Open Kanban Forms}

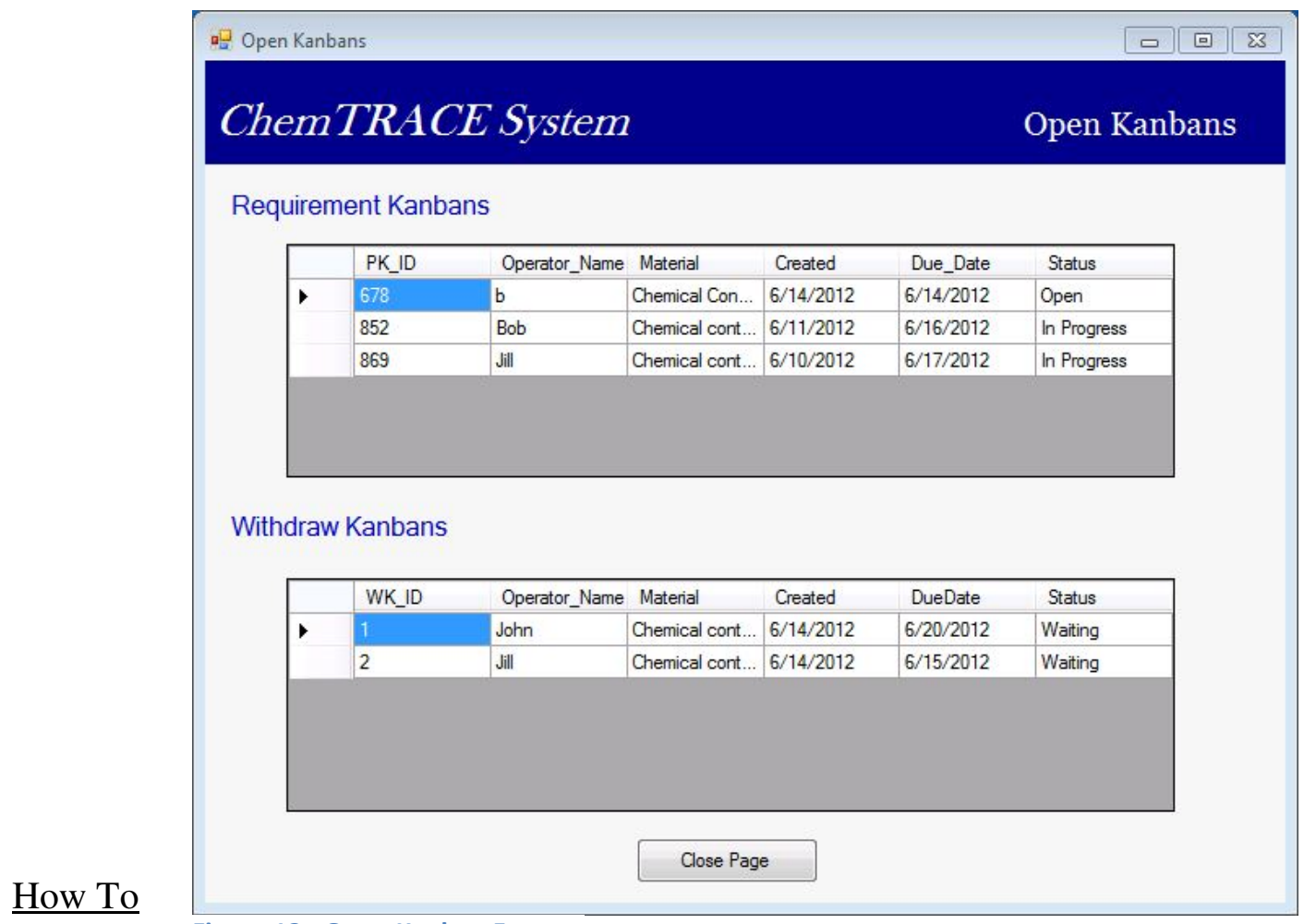

Figure 13 - Open Kanban Form

Access The 


\section{Form:}

You can access the Open Kanban form from the main page by clicking "Open Kanban".

\section{Open Kanban Form Description}

The Open Kanban form (see Figure 13 on page 47) displays all requirement and withdraw kanbans that have not yet been closed. In both the requirement and withdraw kanban grid views display relevant information for an operator or manager to view for an open kanban. This form is meant to be used as an overall general update on all open kanban activity in the ChemTRACE prototype. A user can double click on either the requirement or withdraw kanban grid cells to open up their respective kanban card form which contains more detailed information about the specific kanban.

\subsubsection{Closed Kanbans Form}

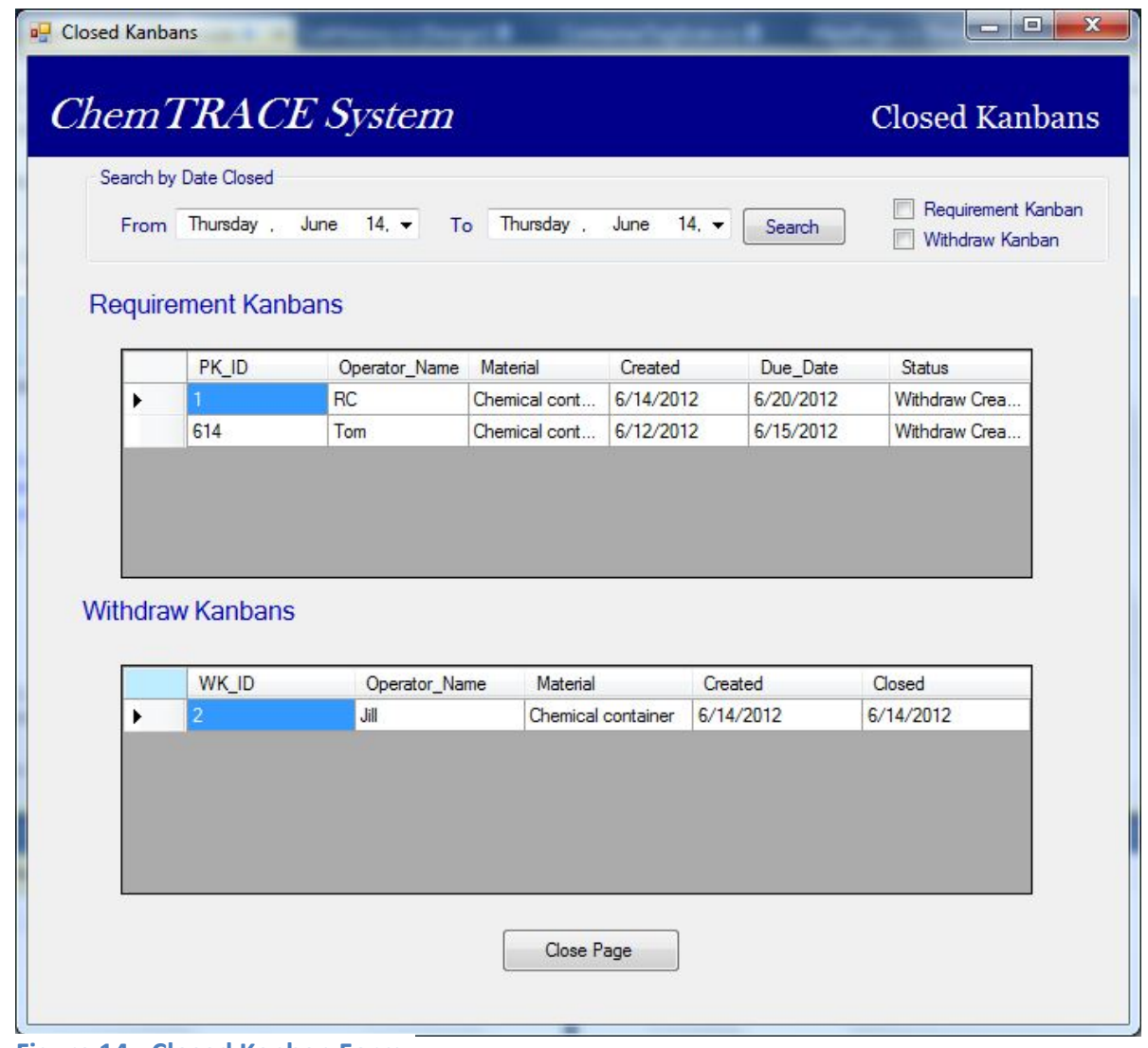

Figure 14 - Closed Kanban Form 


\section{How To Access The Form:}

In the main page click the "Closed Kanbans" button

\section{Closed Kanbans Form Description}

The Closed Kanbans Form (see Figure 14 on page 48) displays all the closed kanbans for both the requirement and withdraw kanban. The user can search for closed kanbans by date closed on either the requirement or withdraw kanban. The user can also double-click on either the requirement or withdraw grid cell to bring up the kanban card form which displays more detailed information.

\subsubsection{Requirement Kanban Card Form}

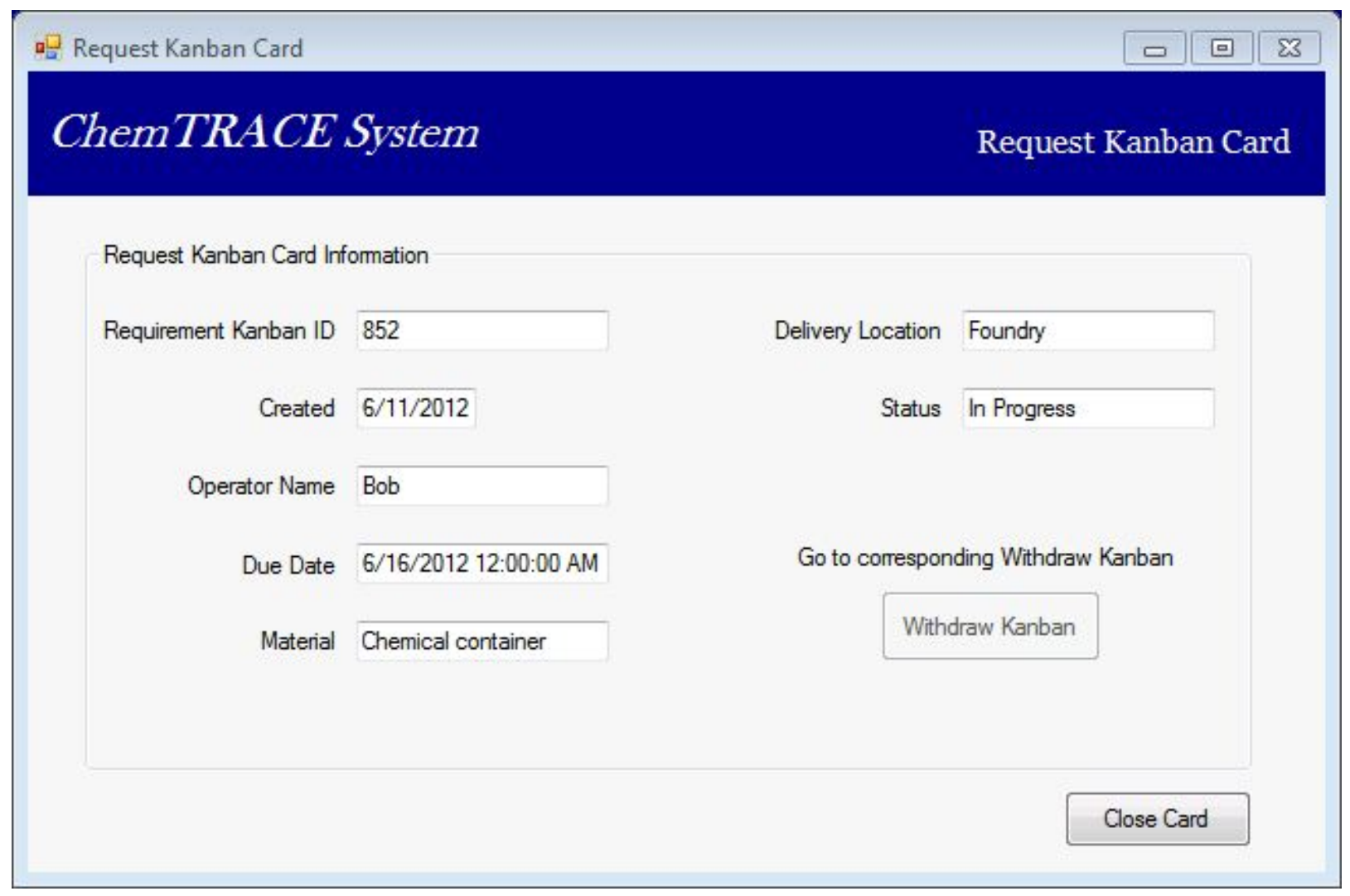

Figure 15 - Requirement Kanban Form 


\section{How To Access The Form}

There are two ways to access the form:

1. Double-click on a cell in the requirement grid view in the Open Kanban form.

2. Double-click on a cell in the requirement grid view in the Closed Kanbans form.

\section{$\underline{\text { Requirement Kanban Card Form Description }}$}

This is the digital form of the requirement kanban card (see Figure 15 on page 49). The requirement kanban card displays all the information that was entered when the kanban card was generated. If an associated withdraw kanban is created, the user will be able to go the corresponding withdraw kanban card (see Figure 16 below) form by clicking the "Withdraw Kanban" button on the bottom right.

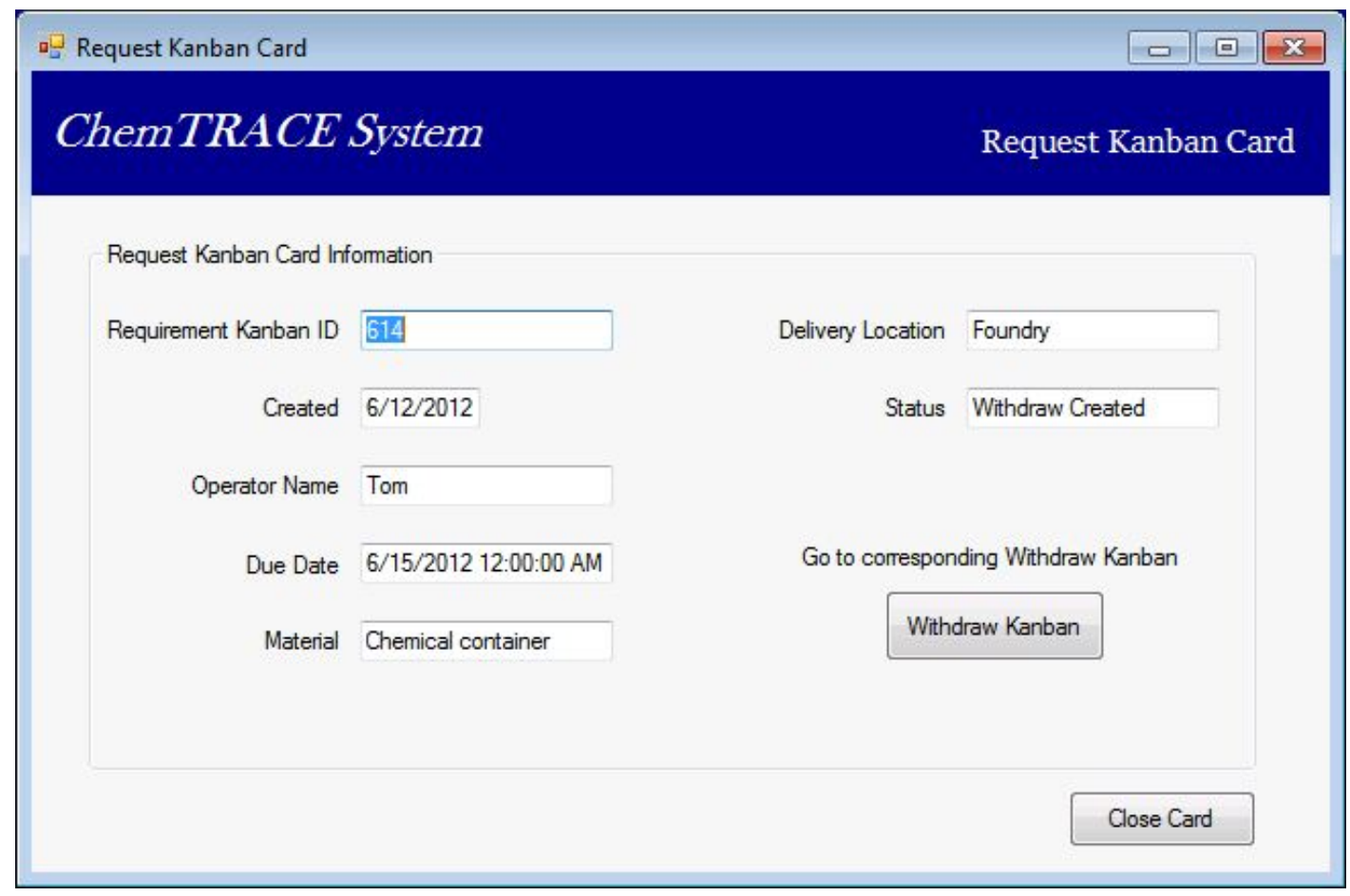

Figure 16 - Requirement Kanban Card with Withdraw Option 


\subsubsection{Withdraw Kanban Card Form}

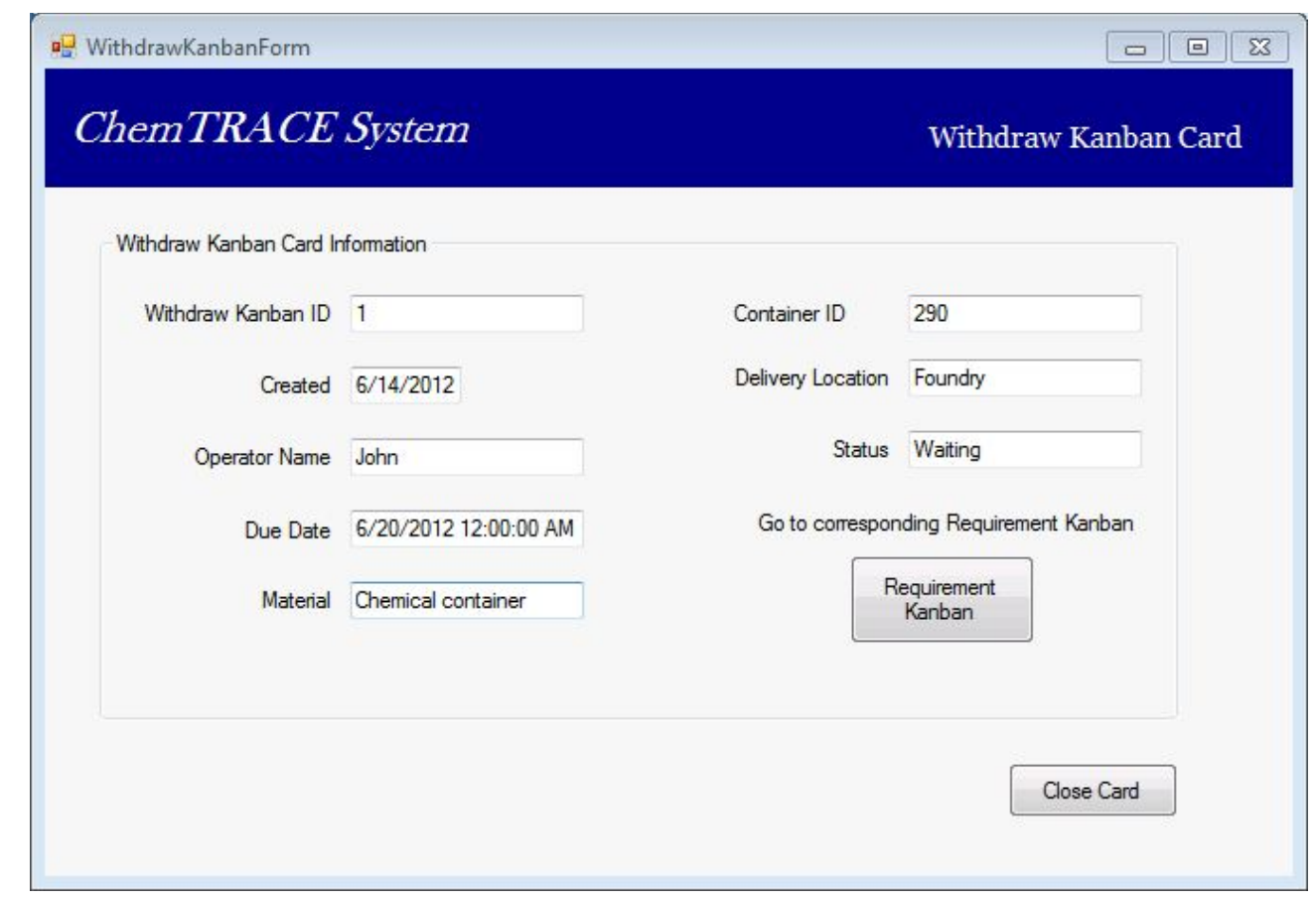

Figure 17 - Withdraw Kanban Card Form

How To Access The Form

There are two ways to access the form:

1. Double-click on a cell in the withdraw kanban grid view in the Open Kanban form.

2. Double-click on a cell in the withdraw kanban view in the Closed Kanbans form.

\section{Withdraw Kanban Card Form Description}

Similar to the Requirement Kanban Card form, this is the digital form of the withdraw kanban card (see Figure 17 above). The withdraw kanban card displays all the information when the kanban card was generated. Since in ChemTRACE, in order for a withdraw card to be generated there must be in existence the associated requirement kanban, the user will always be able to view the associated requirement kanban card. 


\subsubsection{Foundry Page Form}

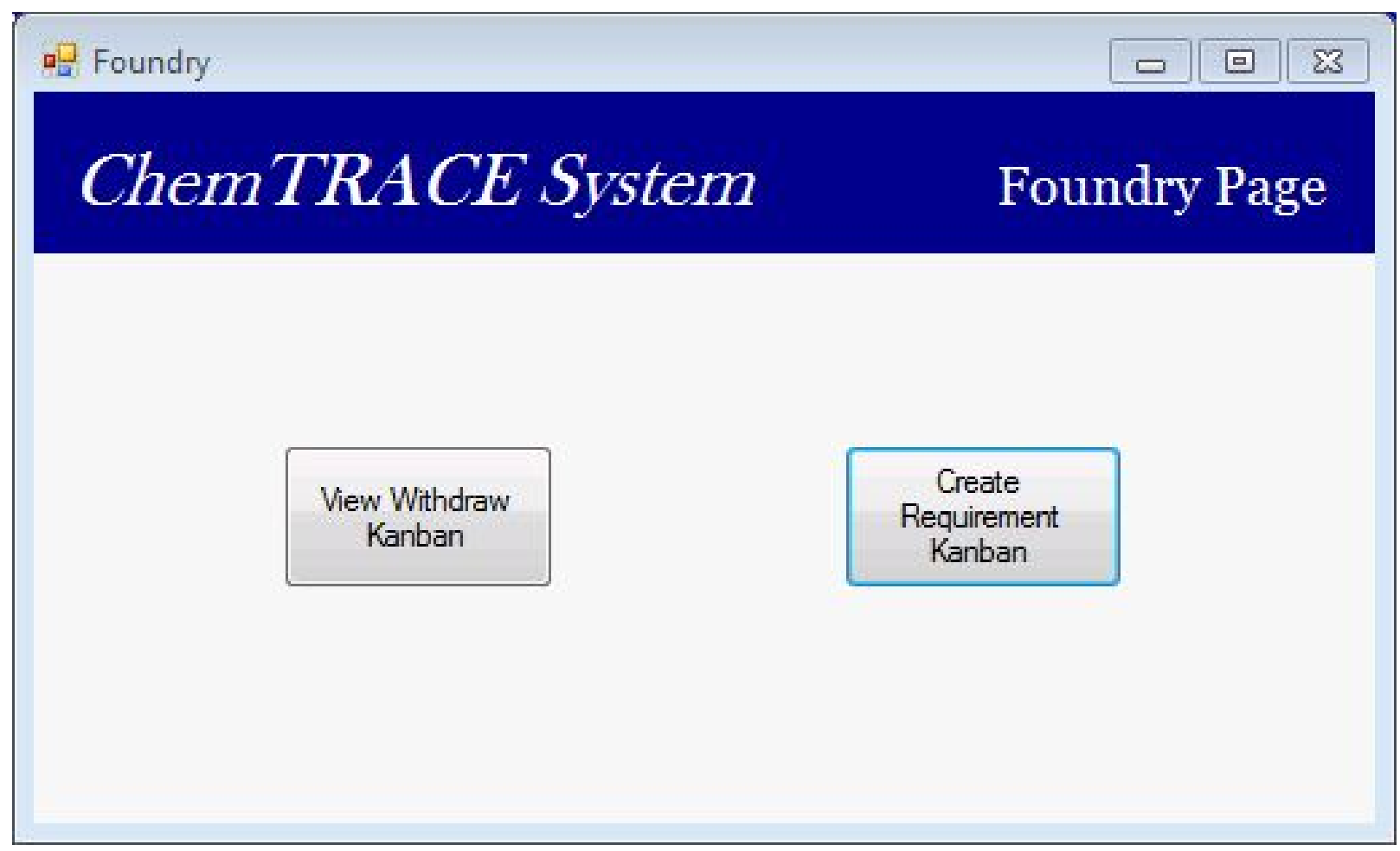

Figure 18 - Foundry Page Form

$\underline{\text { How To Access The Form }}$

From the main screen, login as a foundry operator. This is the first form that will appear after logging in as a foundry operator. The main screen would still be present in the background.

\section{Foundry Page Form Description}

The Foundry Page (see Figure 18 above) form presents the foundry operator access to two forms:

View Withdraw Kanban and Create Requirement Kanban form. None of these forms are available to access to any other type of operator. 


\subsubsection{Create Requirement Kanban Form}

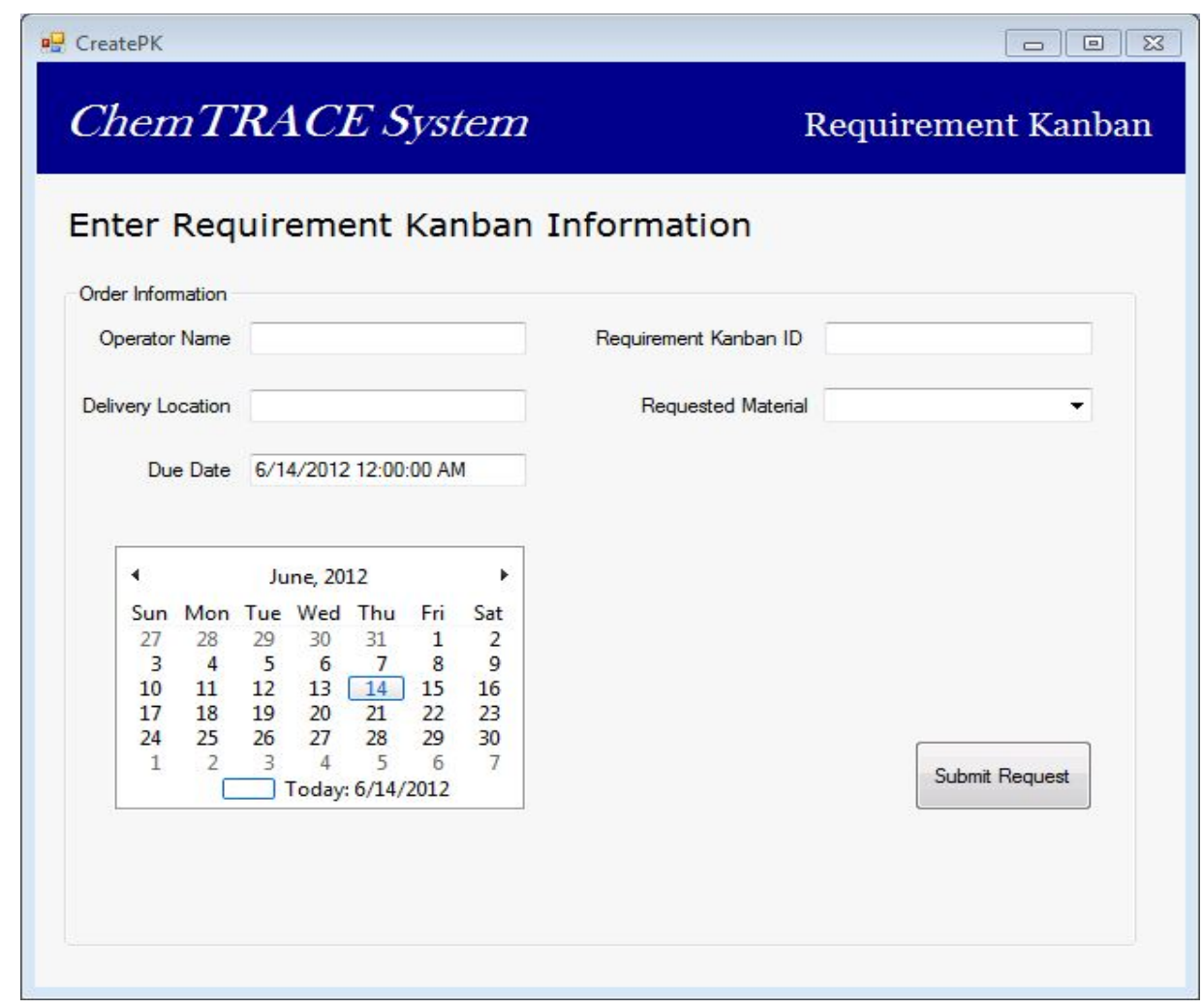

Figure 19 - Create Requirement Kanban Form

How To Access The Form

From the Foundry Page, click the button “Create Requirement Kanban”.

Create Requirement Kanban Form Description

When the foundry requires a chemical container, a Requirement Kanban (see Figure 19 above) is created to inform the storage facility to which chemical container should be delivered. The Requirement Kanban contains information that the storage operator will need to fulfill the request. The following descriptions of each field are as follows.

Field Descriptions below:

- Operator Name - The name of the operator that is creating the kanban. 
- Location - The location of where the container should be delivered.

- Due date - The date when the material should be delivered by.

- Requirement Kanban ID - The identification number of the requirement kanban.

- Requested Material - The type of material/inventory that is being requested. In this system it is a chemical container.

After all the fields are completed, the foundry operator can submit the requirement kanban by clicking the button "Submit Request" in the lower right hand corner. The storage operator will be able to view the requested kanban in their form.

\subsubsection{View Withdraw Kanban Form}

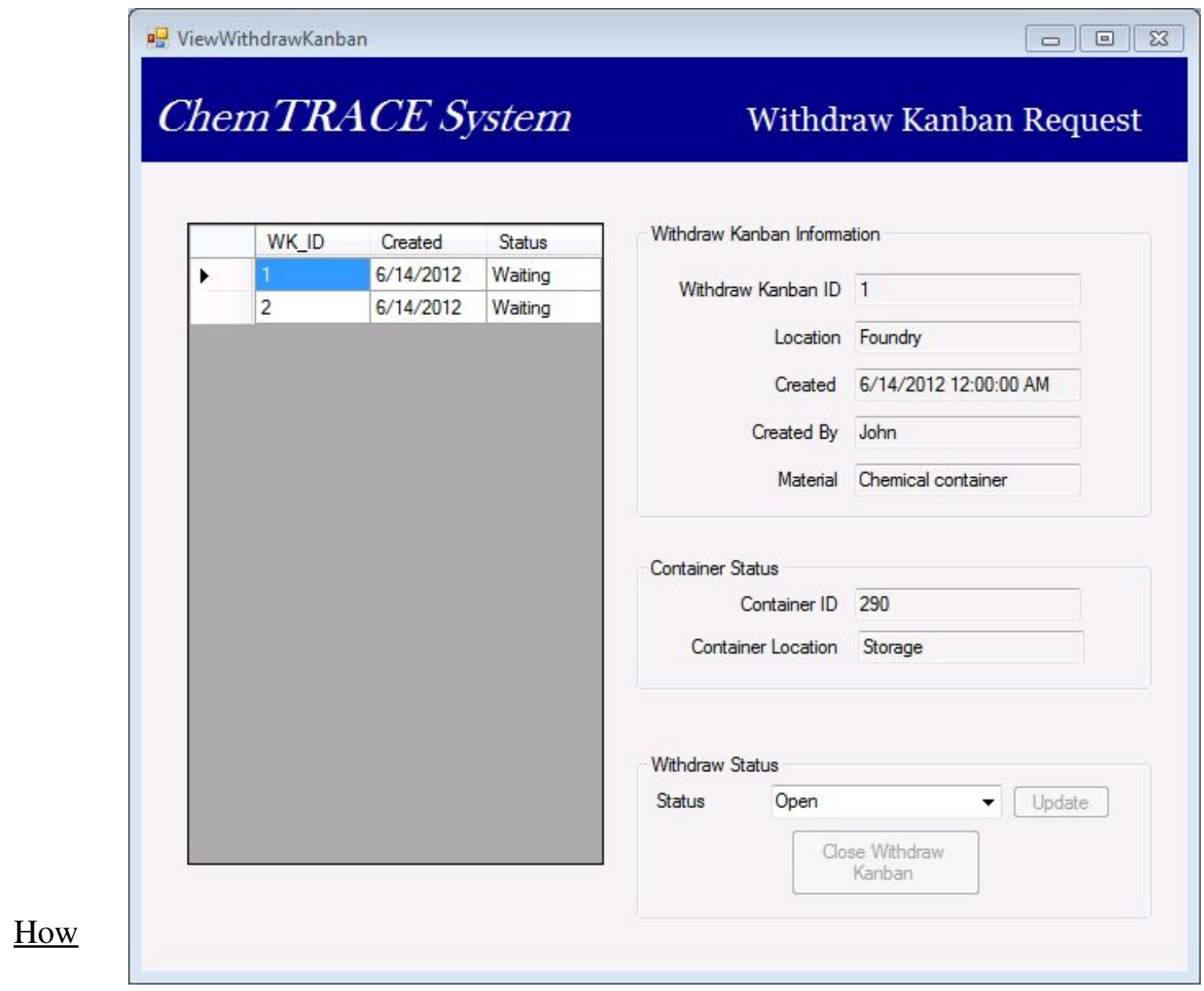

Figure 20 - View Withdraw Kanban Form 


\section{Access The Form}

From the Foundry Page, click the button "View Withdraw Kanban".

View Withdraw Kanban Form Description

The View Withdraw Kanban form (see Figure 20 on page 54) allows the foundry operator to view Withdraw Kanbans that have not yet been closed. The operator can only close the withdraw kanban when the container is detected to be at the same location specified by the Withdraw Kanban, and the withdraw status is updated to "closed". When this happens, the "Close Withdraw Kanban" button is enabled allowing the operator to approve the fulfillment of the withdraw kanban.

\subsubsection{Storage Page Form}

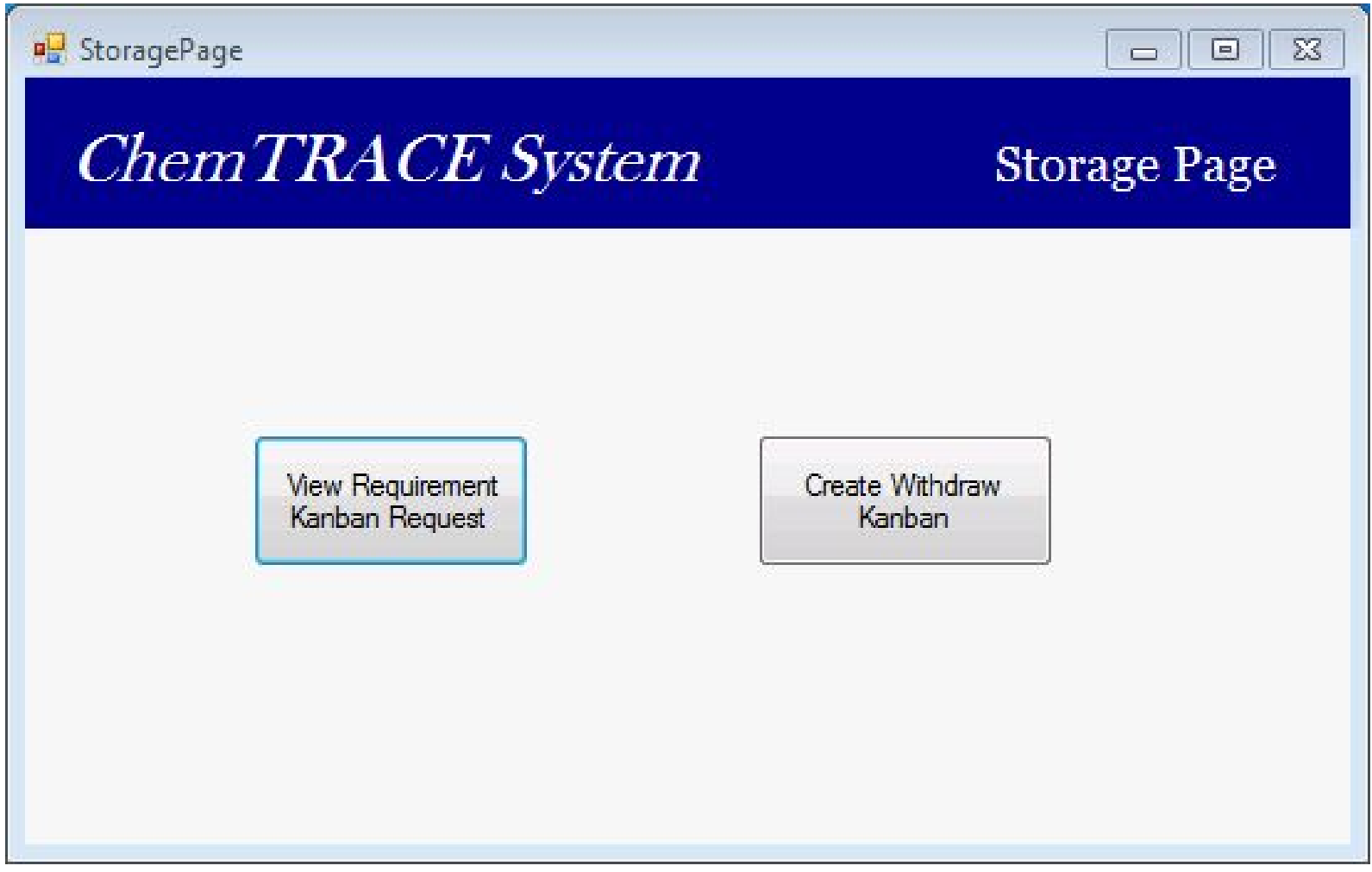

Figure 21 - Storage Page 


\section{How To Access The Form}

Login as a storage operator from the main screen to access the form. This is the first form that will appear after logging in as a storage operator. The main screen would still be present in the background.

\section{$\underline{\text { Storage Page Form Description }}$}

The Storage Page form (see Figure 21 on page 55) presents the storage operator access to two forms: View Requirement Kanban and Create Withdraw Kanban form. None of these forms are available to access to any other type of operator.

\subsubsection{View Requirement Kanban Request Form}

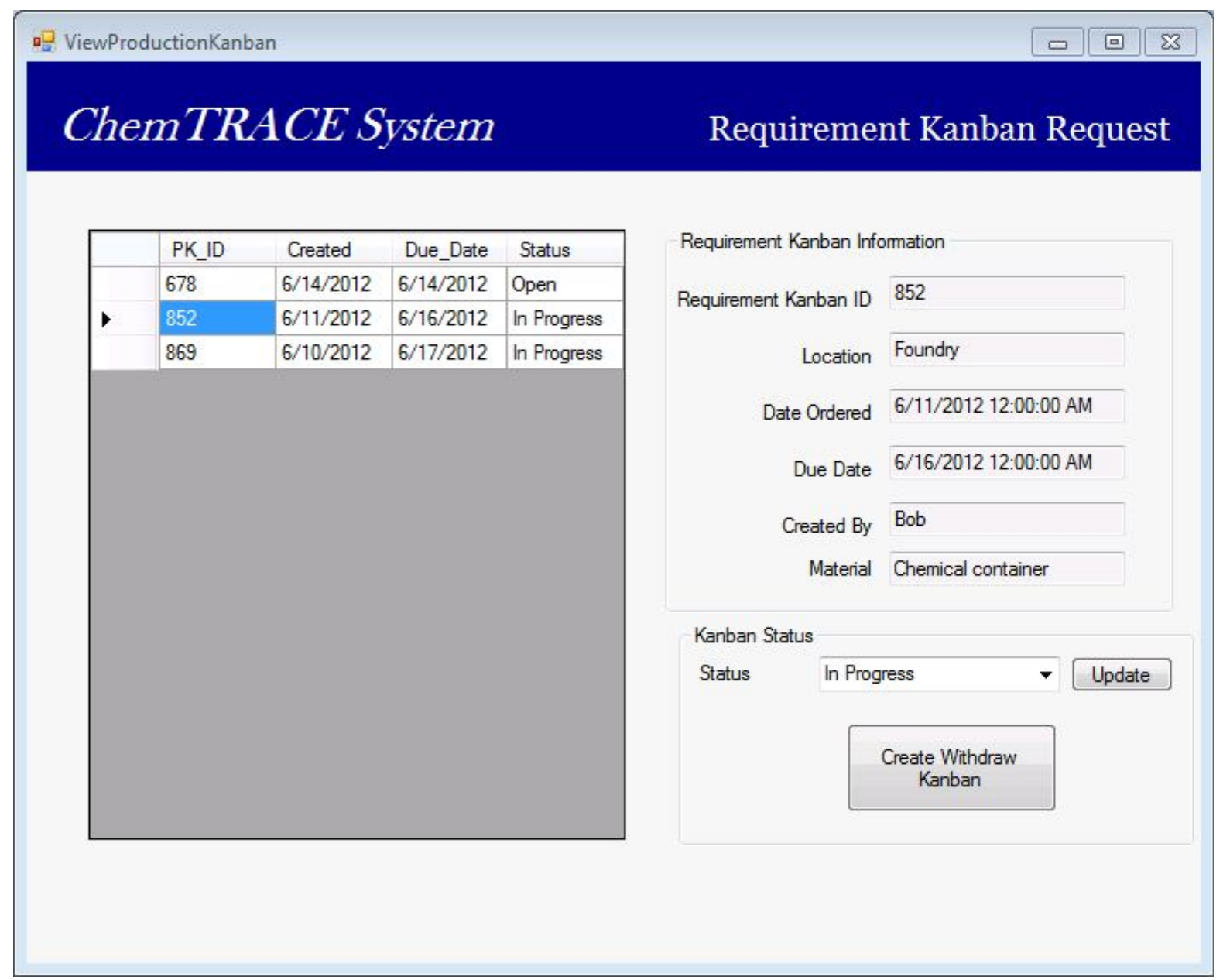

Figure 22 - View Requirement Kanban Request Form 


\section{How To Access The Form}

From the Storage Page, click the button "View Requirement Kanban Request".

\section{View Requirement Kanban Request Form Description}

When the foundry creates a requirement kanban, the storage facility operator can view the kanban on the View Requirment Kanban form (see Figure 22 on page 56). When a requirement kanban is selected in the gird view, detailed information of the kanban is displayed on the right hand side.

When a chemical container is ready to be delivered to the foundry, the foundry operator can create a withdraw kanban by selecting the appropriate requirement kanban in the grid view and clicking the "Create Withdraw Kanban" button in the View Requirement form. The facility operators can also update the progress of the requirement kanban to "in progress" to notify the foundry as to status of the requirement kanban.

\subsubsection{Create Withdraw Kanban Request Form}

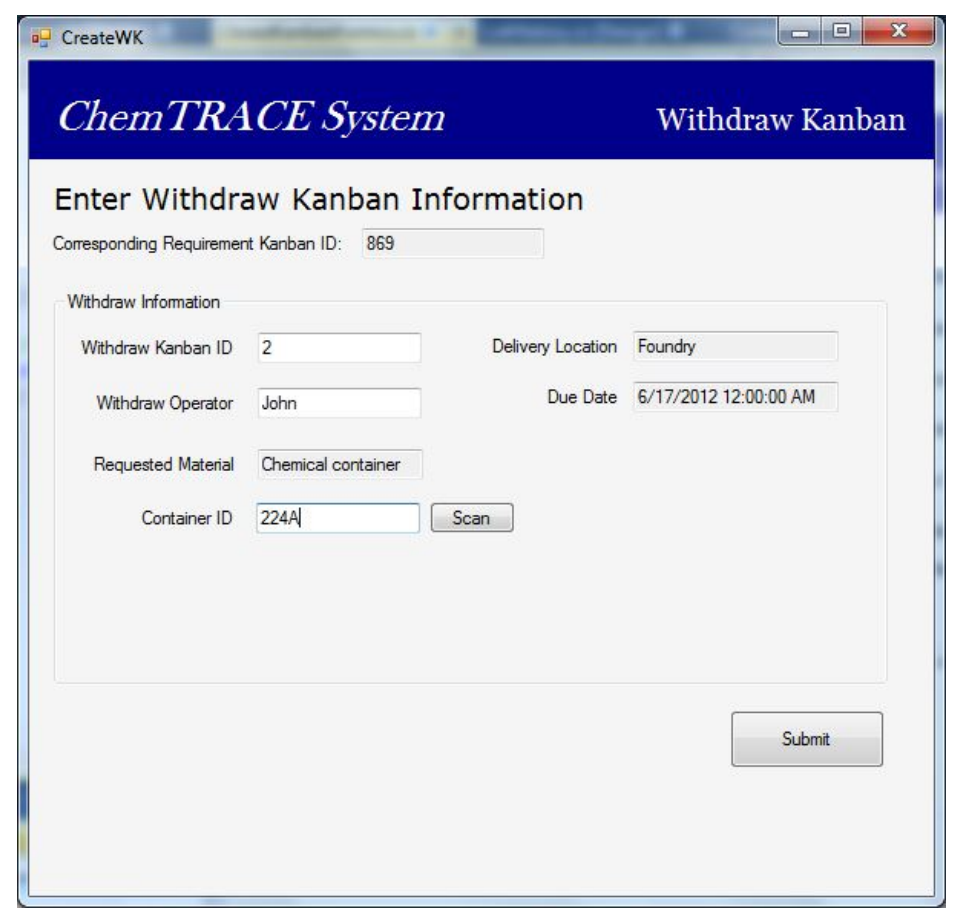

Figure 23 - Create Withdraw Kanban Form 


\section{How To Access The Form}

There are two ways to access the form:

1. From the View Request Kanban form, select the corresponding requirement kanban and click "Create Withdraw Kanban”. (Preferred Method.)

2. From the Storage Page, click the button "Create Withdraw Kanban".

\section{Create Withdraw Kanban Form Description}

This form (see Figure 23 on page 57) allows the storage operator to create a withdraw kanban. When the operator creates the withdraw kanban from the View Request Kanban form, the requested material, delivery location, and due date are automatically populated. In addition to simply filling out information, the operator needs designate which container should be transported. The designated container's RFID tag can be scanned by the RFID system in the storage house. When the operator fills out all the fields then the withdraw kanban can be submitted by clicking the "Submit" button in the bottom right hand corner. The following descriptions of each field are as follows:

- WK_ID - The identification number of the withdraw kanban card.

- Withdraw Operator - The name of the operator that created this kanban card

- Requested Material - The type of material/inventory that is requested. In this system it will be a chemical container.

- Container_ID - The identification number of the associated container with the withdraw kanban card. .

- Delivery Location -The location of where the container is to be delivered.

- Due_Date - The date that the material is to be delivered by. 
Once the operator clicks "Submit", the withdraw kanban is created. The foundry operator can view the created withdraw kanban in the form "View Withdraw Kanban". (See section 5.4.11)

\subsection{Cost of Implementation}

The cost associated with the ChemTRACE prototype includes expenses in hardware and software. Note that the cost of the hardware and software in this section are current retail prices and are subject to change. Some costs may be estimated. (The estimated cost will be denoted with $\mathrm{a}^{*}$.) This section covers the cost for current implementation.

\subsubsection{Hardware Cost}

The cost for the hardware components are listed below in Table 5.

Table 5 - Hardware Cost

\begin{tabular}{|c|c|c|c|}
\hline Item & Cost per Item & Quantity & Cost \\
\hline Sirit 510 & $\$ 1,500$ & 2 & $\$ 3,000$ \\
\hline RFID UHF Tags & $\$ .35$ & 500 & $\$ 175$ \\
\hline Antenna & $\$ 150$ & 2 & $\$ 1200$ \\
\hline Computer* & $\$ 1000$ & 2 & $\$ 2000$ \\
\hline Network cables (50 ft)* & $\$ 20$ & 1 & $\$ 40$ \\
\hline Network Router* & $\$ 70$ & Total Cost & $\sim \$ 6,500$ \\
\hline
\end{tabular}

* Estimated price 


\subsubsection{Software Cost Support}

Software support for the ChemTRACE prototype includes any updates or code changes that need to be made to the current system. The software programmer is estimated to spend 40 hours on learning and writing code to support the system (see Table 6 below).

Table 6 - Software Support Cost

\begin{tabular}{|c|c|c|c|}
\hline Item & Cost per Hour & Estimated Hours & Cost \\
\hline Software Programmer & $\$ 40$ & 40 & $\$ 1,600$ \\
\hline & & Total Cost & $\$ 1,600$ \\
\hline
\end{tabular}

\subsubsection{Integration Cost}

Integration cost includes the cost of initial labor and setup for the ChemTRACE prototype. See Table 7 below.

Table 7 - Integration Cost

\begin{tabular}{|c|c|c|c|c|}
\hline Item & Cost per Hour & Estimated Hours & Quantity & Cost \\
\hline $\begin{array}{c}\text { Engineering } \\
\text { Intern }\end{array}$ & $\$ 20$ & 180 & 2 & $\$ 3,600$ \\
\hline & & & Total Cost & $\$ 3,600$ \\
\hline
\end{tabular}

\subsubsection{Total Cost}

Table 8-Total Cost Estimate

Component

Hardware

\section{Cost}

$\$ 6,500$ 


\begin{tabular}{|c|c|}
\hline Software Support & $\$ 1,600$ \\
\hline Integration & $\$ 3,600$ \\
\hline Total Cost & $\$ 11,700$ \\
\hline
\end{tabular}

The total estimated cost to implement the ChemTRACE prototype is $\$ 11,700$. This is the estimated cost of hardware, software, and integration support for the ChemTRACE prototype (see Table 8 above).

\subsection{Implementation Plan For ChemTRACE}

ChemTRACE is going to be implemented in the summer of 2012 at the Department of Defense facility as described in this case study. To help with implementation, the author will train and assist engineers to full system implementation. This includes both software assistance and hardware support. There is a possibility of future expansion of the ChemTRACE prototype to other areas in the facility that would include tracking other WIP inventory.

\subsection{ChemTRACE Evaluation}

This section will review the four objectives of building a REK prototype with the creation ChemTRACE prototype.

\section{- Develop a REK Prototype that supports Continuous Improvement}

Collecting and analyzing WIP production data is a valuable asset when selecting project improvement plans. Since ChemTRACE collects and stores all the data electronically, the data can easily be accessed through the system's database to be viewed and analyzed. It is important to note that viewing and analyzing data itself is not continuous improvement, 
but the reports generated from the data can suggest major project improvements that would have been otherwise hard to justify.

The ChemTRACE prototype also has the ability to limit the circulation of kanban cards (which has been calculated to five cards) and can lower card levels which can reveal process inefficiencies. When there is lower levels of inventory, production inefficiencies can be better observed. In a manual card based system, if managers wanted to lower kanban card circulation they would have to manually go around the entire facility to collect the cards to decrease the volume of the cards. In ChemTRACE, lowering kanban card volume can be quick and automatic in an electronic system.

The ChemTRACE prototype allows for better supply chain visibility. Supply chain visibility supports and benefits the goals JIT manufacturing. Clearer supply chain visibility allows better communication with other suppliers and partners along the supply chain. The availability for the data to be accessed electronically in ChemTRACE helps achieves better supply chain visibility and can lead to better coordination with other suppliers and partners.

\section{- Reduce overall non-value added waste in the material flow process}

The DoD facility does not have any automatic system to track the location history of the chemical containers. This has important implications for post-production tracking. Since these chemicals were being applied to microchips, if there was a microchip failure due to chemical treatment, it could be difficult or time consuming to find which container was used. Second, there must be accountability as to the current location of all chemical containers. The facility cannot afford to lose any containers as they are very expensive and contain hazardous chemicals. The RFID component in the ChemTRACE prototype 
allows for real time location updates and tracks the location history of the container which reduces time spent looking and investigating its whereabouts.

Replacing physical kanban cards with electronic signals in ChemTRACE reduces several non-value added waste. The first is the elimination of losing physical kanban cards. When a physical card is lost, workstation production ceases until the card is found or a new one is generated. Lost cards increase lead time and expenses. The second is the efficiency and quickness of an electronic kanban signal over a physical card. It is common for workstations to receive and send kanban cards once every receiving/sending time cycle. With an electronic signal, the receiving and sending out kanban cards is instant. The third is the elimination or reduction of tasks for the kanban logistics operator. While the role of the kanban logistics operator may differ from company to company, the task of picking up physical kanban cards is no longer necessary. This saves people resource in a facility. A fourth advantage is the elimination of manual paper reports and records. Facilities that use a large volume of physical kanban cards sometimes keep large paper records of kanban statistics and kanban history records. Gathering and analyzing data from paper records is tedious and time consuming. ChemTRACE gathers data automatically and can feed data to generate reports faster than a manual based paper system.

ChemTRACE also reduces the non-value waste of mismanagement on chemical container inventory. Communication between two workstations is necessary for everyday production flow. ChemTRACE is built to display up to date kanban request and statuses. There is a clear flow of communication between the workstations in the system. And 
since every kanban card requires an operator name, there is accountability in the system in case if any process is not followed.

\section{- REK must be intuitive and simple to use for the operator}

The GUI of the ChemTRACE prototype was built to be simple and intuitive for the operator. All buttons are labeled according to their functionality and all forms are clearly titled and visible. If an operator tries to submit a form without filling out all the fields, the system will communicate to the operator which fields need to be filled out.

Presenting general and specific operator tasks was developed to be simple and straight forward as possible. Since viewing container or kanban information is a frequent task, the form availability to access the container and kanban information forms was placed on the main screen. Specific operator tasks are shown by logging into ChemTRACE. These specific tasks are labeled and clearly visible after logging in.

\section{- REK prototype control is de-centralized}

In the original kanban system, operators are empowered since the decision of generating and filling kanban cards was their responsibility. The ChemTRACE prototype was built as a de-centralize control system in order to empower the operators. In both the foundry and storage facility, only the respective operator can generate and close their respective kanban cards. Also in the ChemTRACE prototype, the flow of chemical containers to and from the foundry area is controlled through a visual signal that can be seen on the computer. Controlling production flow through a visual signal was one of the characteristics of a de-centralize kanban system. 


\section{Chapter 6: Conclusion}

The development of a REK prototype was explained and described in detail. The building of the ChemTRACE prototype was based upon a general REK model in which REK objectives were determined by analyzing the original kanban system and lean principles. To build ChemTRACE, DoD facility requirements required adaptations and modifications in the REK general model. The ChemTRACE prototype was built as a prototype for the DoD facility to facilitate chemical flow between the foundry and storage area. After completion, ChemTRACE was then analyzed with respect to meeting REK objectives. 


\section{List of References}

[1] Kouri, I. A., Salmimaa, T. J. and Vilpola, I. H., The principles and Planning Process of an Electronic Kanban System, 19th International Conference on Production Research

[2] Lage Junior, M., \& Godinho Filho., M. (2010). Variations of the Kanban system: Literature review and classification. International Journal of Production Economics, 125(1), 13-21.

[3] Ansari and Modarress, "Wireless Kanban," Production and Inventory Management Journal. Vol. 36, No. 1, 1995, pp. 60-64.

[4] Patti, A. L. and Narsing, A. (2008) RFID and Lean: Friends or Foes?, Journal of Business and Economics Research, 6(2):83-90.

[5] Su, Weixing, Lianbo Ma, Kunyuan Hu, and Lei Zhang. "A Research on Integrated Application of RFID based Lean Manufacturing." Control and Decision Conference (2009): $5781-784$.

[6] Sanghera, Paul. RFID+ Study Guide and Practice Exam. Rockland, MA: Syngress, 2007. Print.

[7] Liker, Jeffrey K. The Toyota Way: 14 Management Principles from the World's Greatest Manufacturer. New York: McGraw-Hill, 2004. Print.

[8] Womack, James P., and Daniel T. Jones. Lean Thinking: Banish Waste and Create Wealth in Your Corporation. New York, NY: Simon \& Schuster, 1996. Print.

[9] J. Collins, "DaimlerChrysler Putting RFID Tags in Kanban Cards," RFID Journal, June 7, 2006, http://www.rfidjournal.com/article/view/2405/1 
[10] R. Wessel, “RFID Kanban System Pays Off for Bosch,” RFID Journal,May 7, 2007, http://www.rfidjournal.com/article/view/3293

[11] ZhangY, PingyuJ, HuangG (2008)RFID-based Smart Kanbans for Just-in- Time Manufacturing.International Journal of Materials and Product Technology 33(1/2):170-184.

[12] Wasserman, Elizabeth. "Find the Right RFID Formula.” RFID Journal September/October 2005, http://www.rfidjournal.com/magazine/article/1935

[13] "The Cal Poly RFID Lab." The Cal Poly RFID Lab. N.p., n.d. Web. 17 Mar. 2012. $<\mathrm{http}: / /$ www.polygait.calpoly.edu/>.

[14] Sugimori, Y., K. Kusunoki, F. Cho, and S. Uchikawa. "Toyota Production System and Kanban System Materialization of Just-in-time and Respect-for-human System." International Journal of Production Research 15.6 (1977): 553-64. Print.

[15] Riezebos, Jan, and Warse Klingenberg. "Advancing Lean Manufacturing, the Role of IT." Computers in Industry 60.4 (2009): 235-36. Print.

[16] Jarupathirun, Suprasith, Andrew P. Ciganek, Thaloengsak Chotiwankaewmanee, and Chayanun Kerdpitak. "Supply Chain Efficiencies Through E-Kanban: A Case Study." International Journal of the Computer, the Internet and Management, 17.SP1 (2009). Print.

[17] N. Huber, K. Michael, and L. McCathie. Barriers to RFID adoption in the supply chain. In RFID Eurasia, 2007 1st Annual, pages 1\{6, 2007.

[18] "Calculating the Number of Kanbans/Kanban Quantity." Calculating the Number of Kanbans/Kanban Quantity. Web. 26 June 2012. 
<http://help.sap.com/saphelp_40b/helpdata/en/cb/7f8c3943b711d189410000e829fbbd/content.ht $\mathrm{m}>$.

[19] Woolstenhulme, Jeff. "Back-end Assembly: Closing the Traceability Gap." Back-end Assembly: Closing the Traceability Gap. N.p., n.d. Web. 04 July 2012.

$<$ http://www.electroiq.com/articles/ap/print/volume-10/issue-10/departments/industryvoices/back-end-assembly-closing-the-traceability-gap.html>.

[20] Kelepouris, Thomas, Katerina Pramatari, and Georgios Doukidis. "RFID-enabled Traceability in the Food Supply Chain." Industrial Management \& Data Systems 107.2 (2007): 183-200. Print.

[21] Petri, Daniel. "OSI Model Concepts." OSI Model Concepts. Web. 29 June 2012. $<$ http://www.petri.co.il/osi_concepts.htm>.

[22] Potter, Dick, Ron Bowman, and Laura Peters. "Cost Per Wafer." Cost Effective IC Manufacturing, 1998-1999. Scottsdale, AZ: Integrated Circuit Engineering, 1997. N. pag. Print. 


\section{Appendix A: Production Kanban Operator Workflow}

$\underline{\text { Production Kanban Initial Stage Operator Workflow }}$

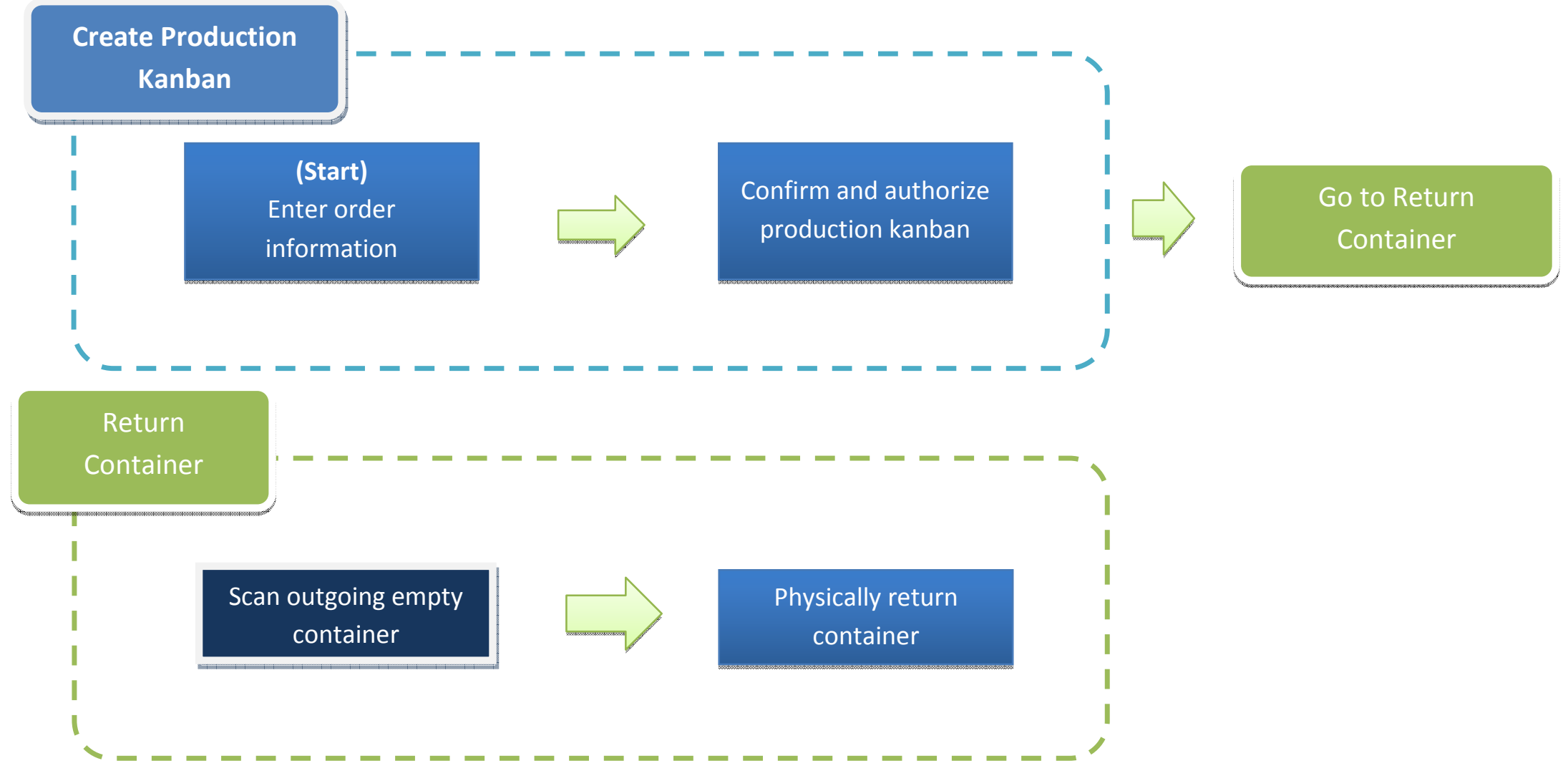




\section{Production Kanban Final Stage Operator Workflow}
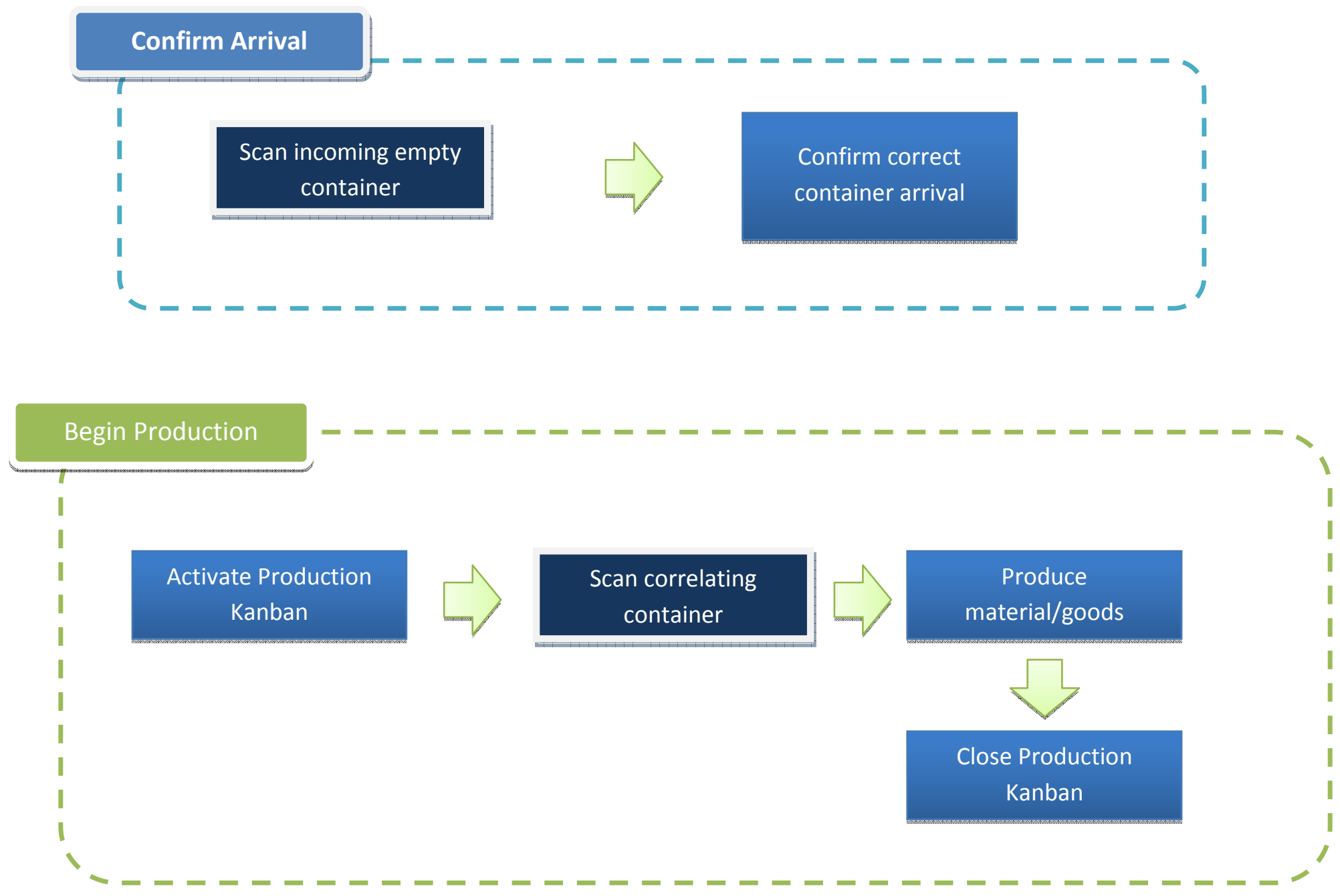


\section{Appendix B: Withdraw Kanban Operator Workflow}

Withdraw Kanban Initial Stage Operator Workflow

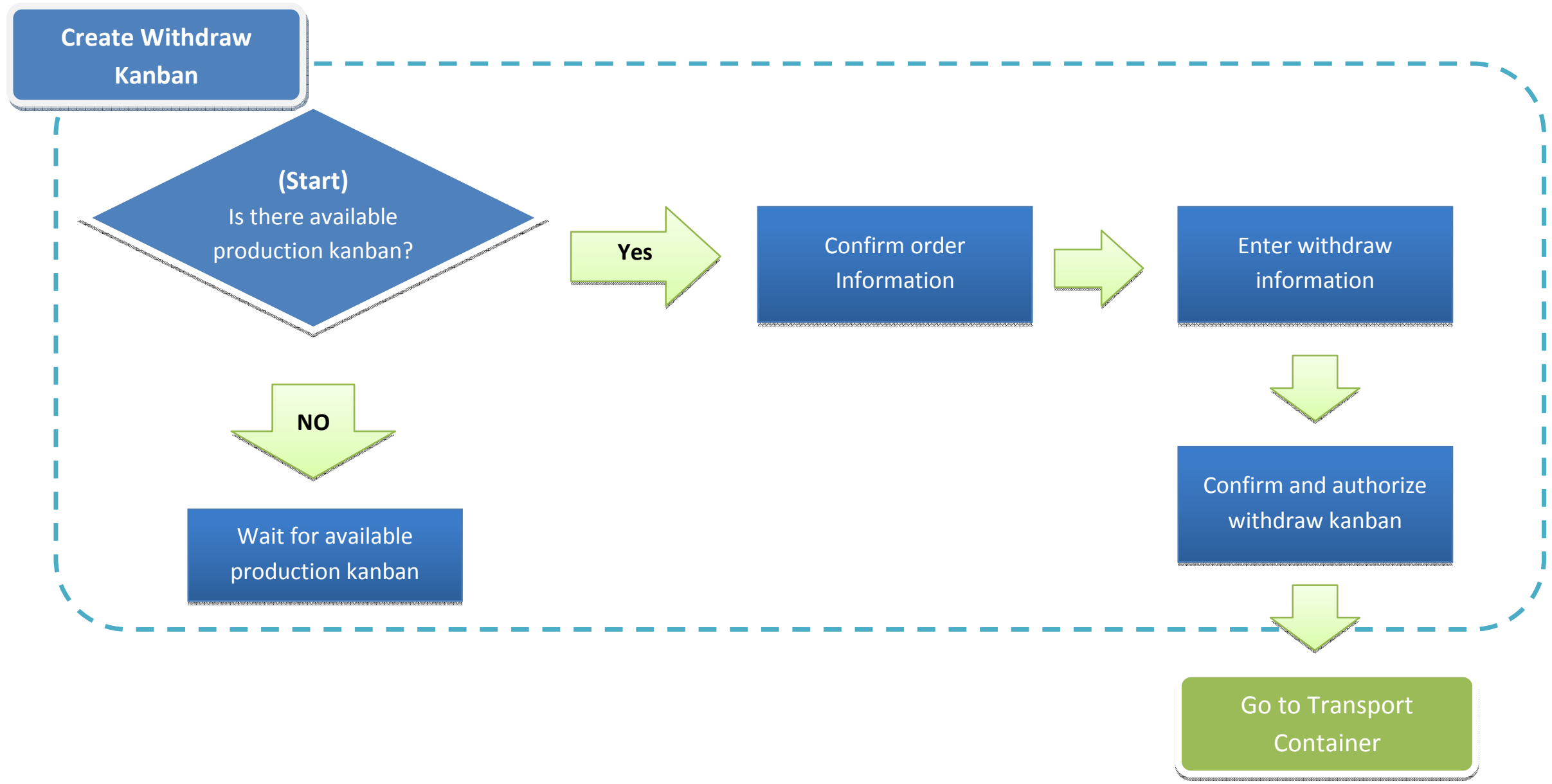

(See Next Page) 
Withdraw Kanban Initial Stage Operator Workflow (Continue)

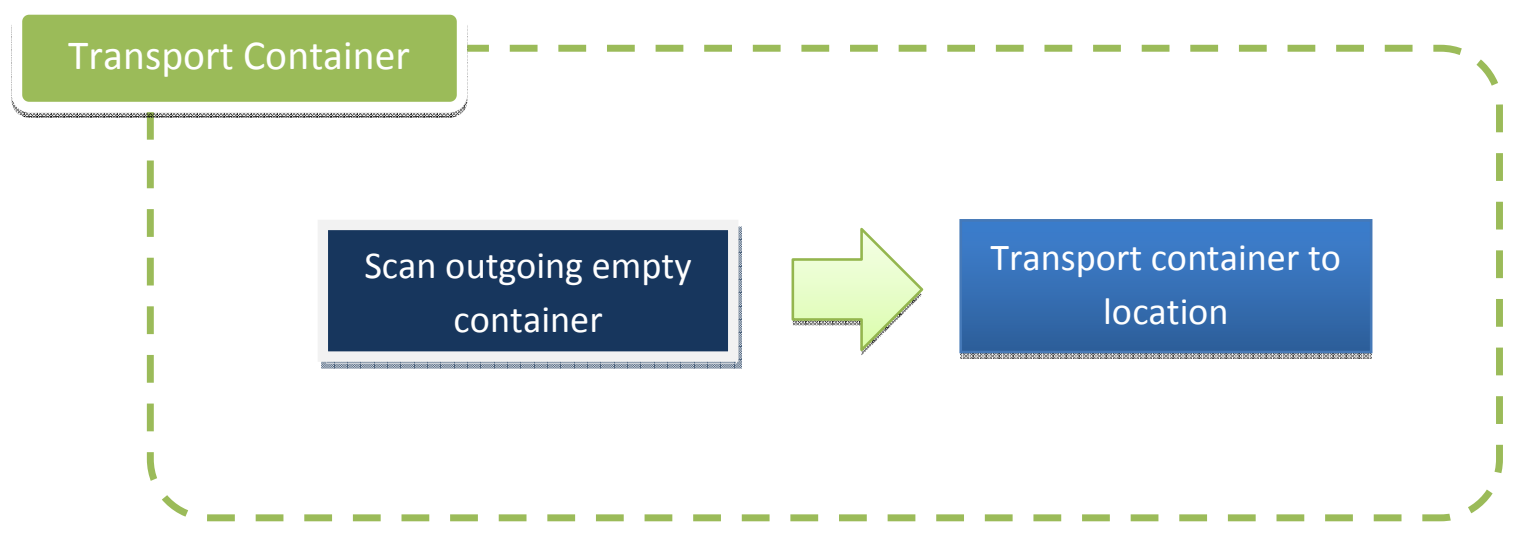

\section{Production Kanban Final Stage Operator Workflow}

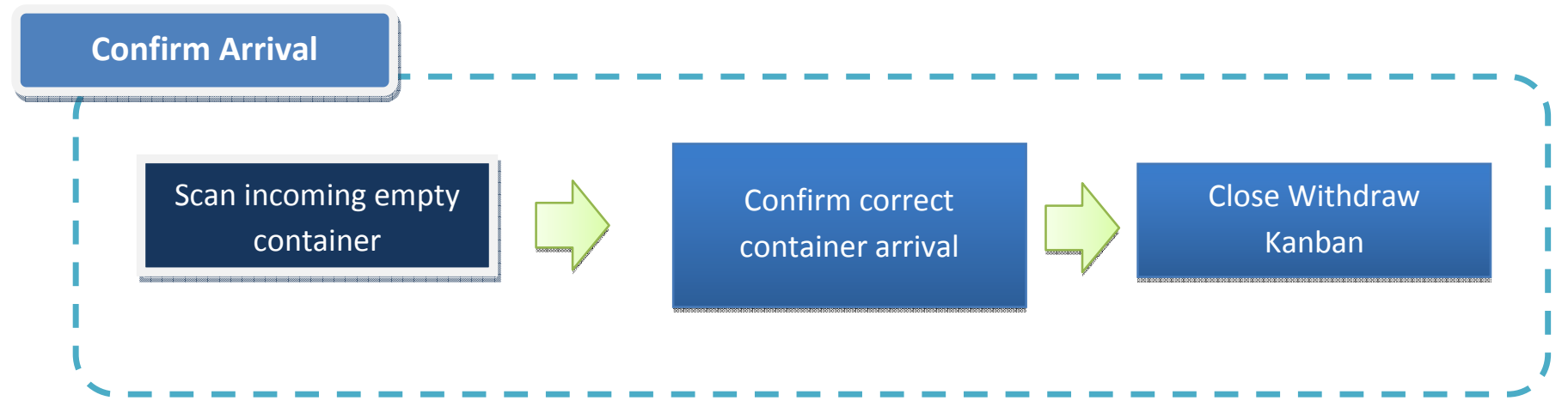




\section{Appendix C: Cotton, Keith, Personal Communication}

(Blackouts are applied to the official name the DoD facility)

RFID inventory system proposal for chemical inventory and PAS Lab

By Keith Cotton -

needs to monitor and automate the chemical inventory storage and movement of controlled chemicals from storage to the foundry and the return to storage. The PAS Lab will be using RFID tags to monitor piece parts and will require a small RFID tag.

Items that need to be addressed:

Locate or develop RFID tags that will work on a container of liquid and small packages.

Have the vendor add RFID tags on container prior to shipment to

Possibly receive shipment using RFID.

Review interface possibilities with current in house applications.

View chemical inventory and PAS Lab via RFID.

Recommend hardware needed with cost.

Recommend software needed with cost.

Survey for antenna placement.

Develop program for RFID to recognize a removal from stock and a return to stock.

Provide training

Provide timely updates 


\section{Appendix D: Selected ChemTRACE Software Code}

The two classes of code were selected because of their functional importance of controlling with the RFID hardware and updating tag location.

\section{$\underline{\text { Sirit Reader Setup Class }}$}

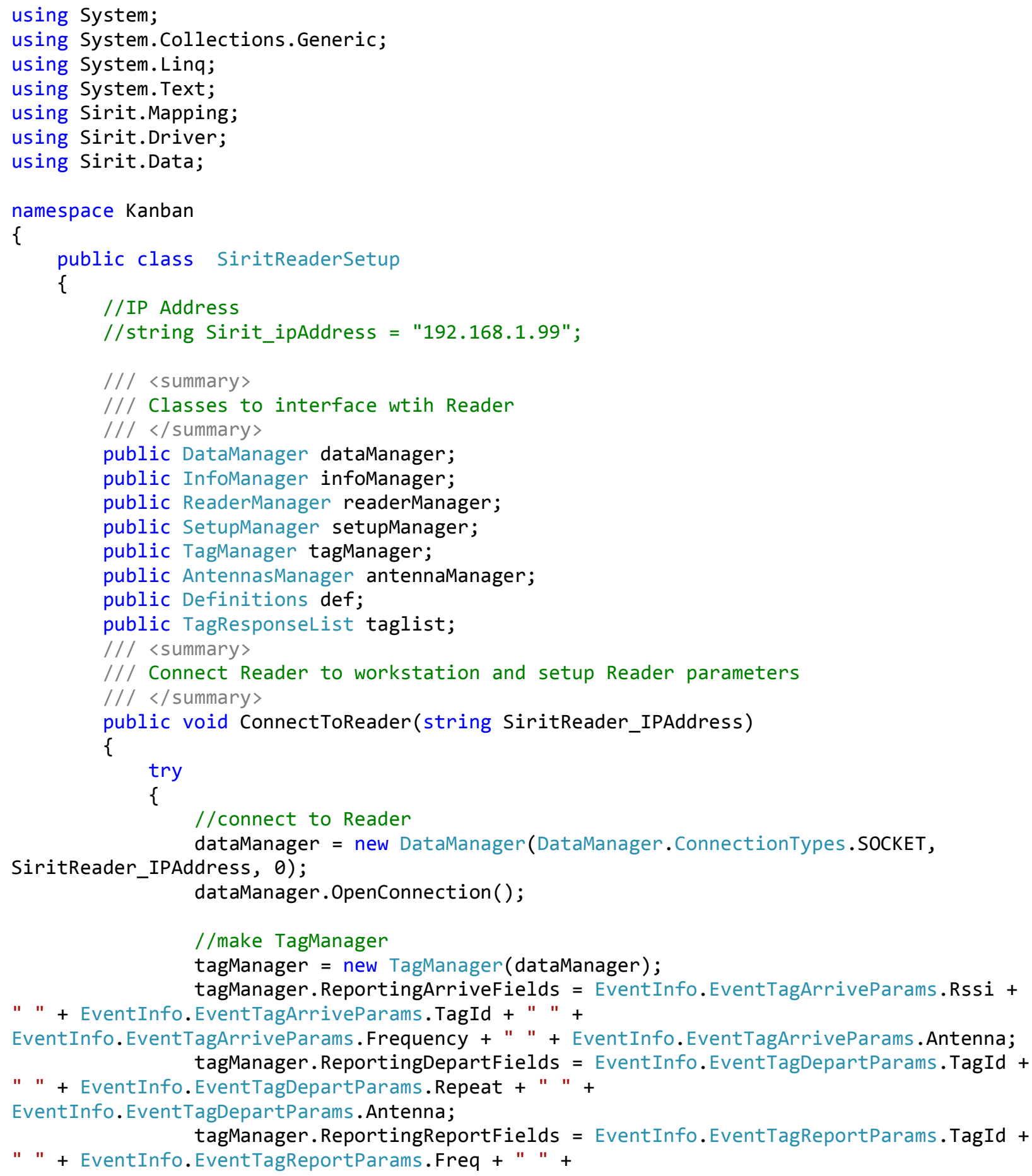




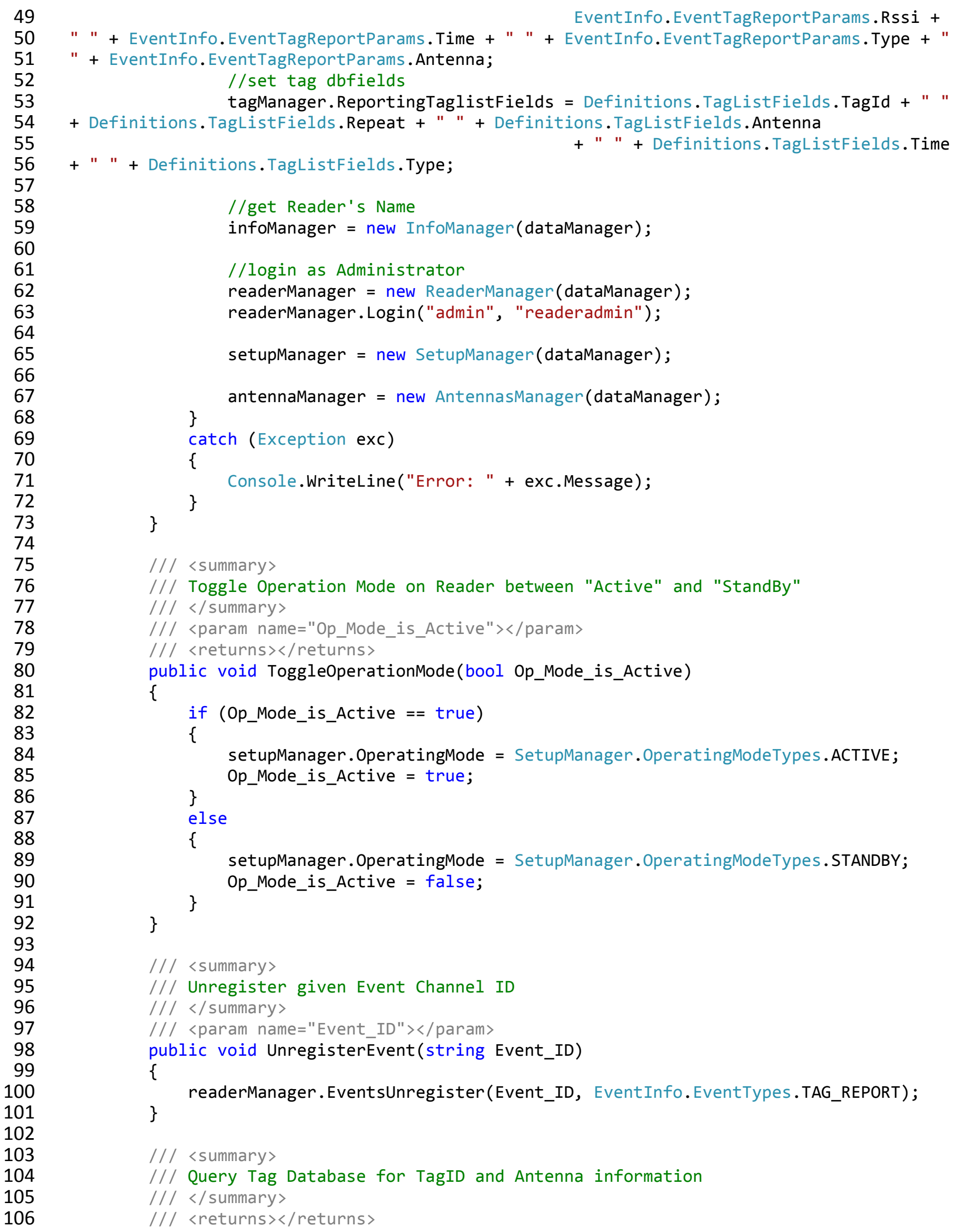




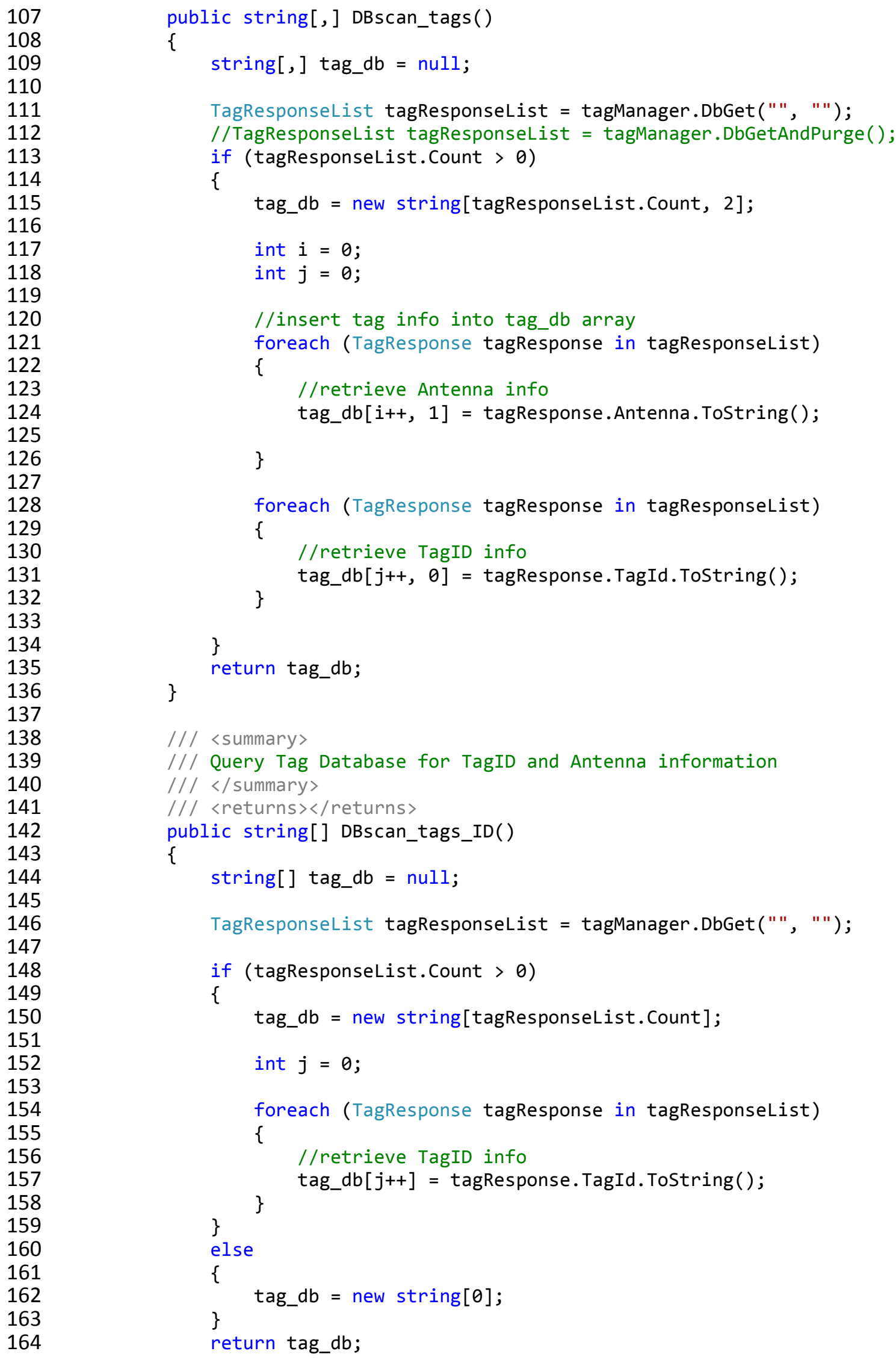




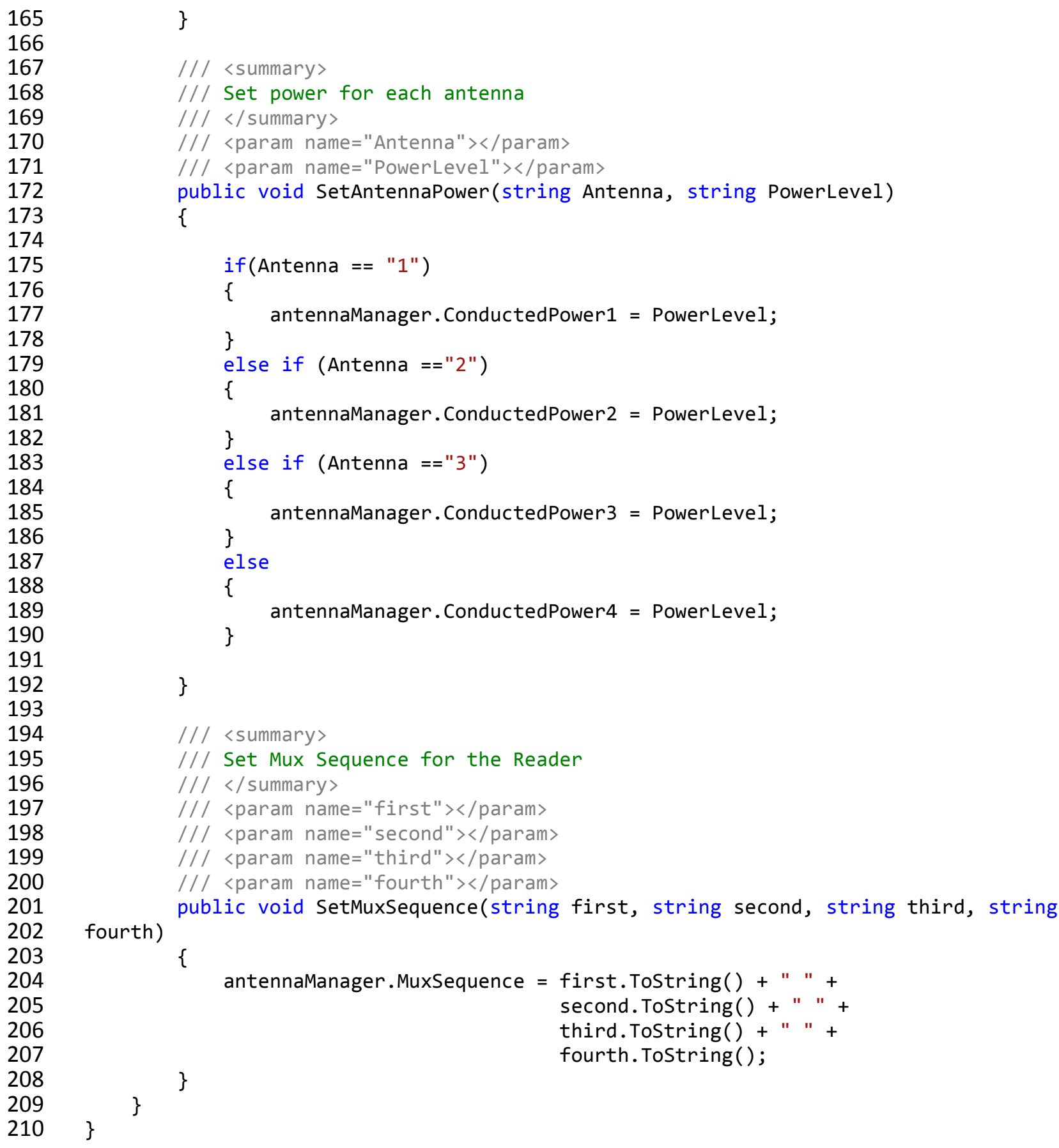

\section{$\underline{\text { Update Location Tag Class }}$}

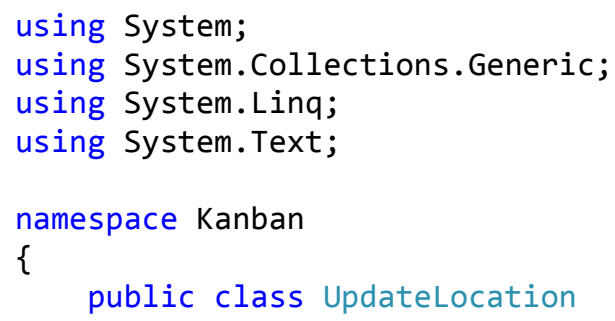




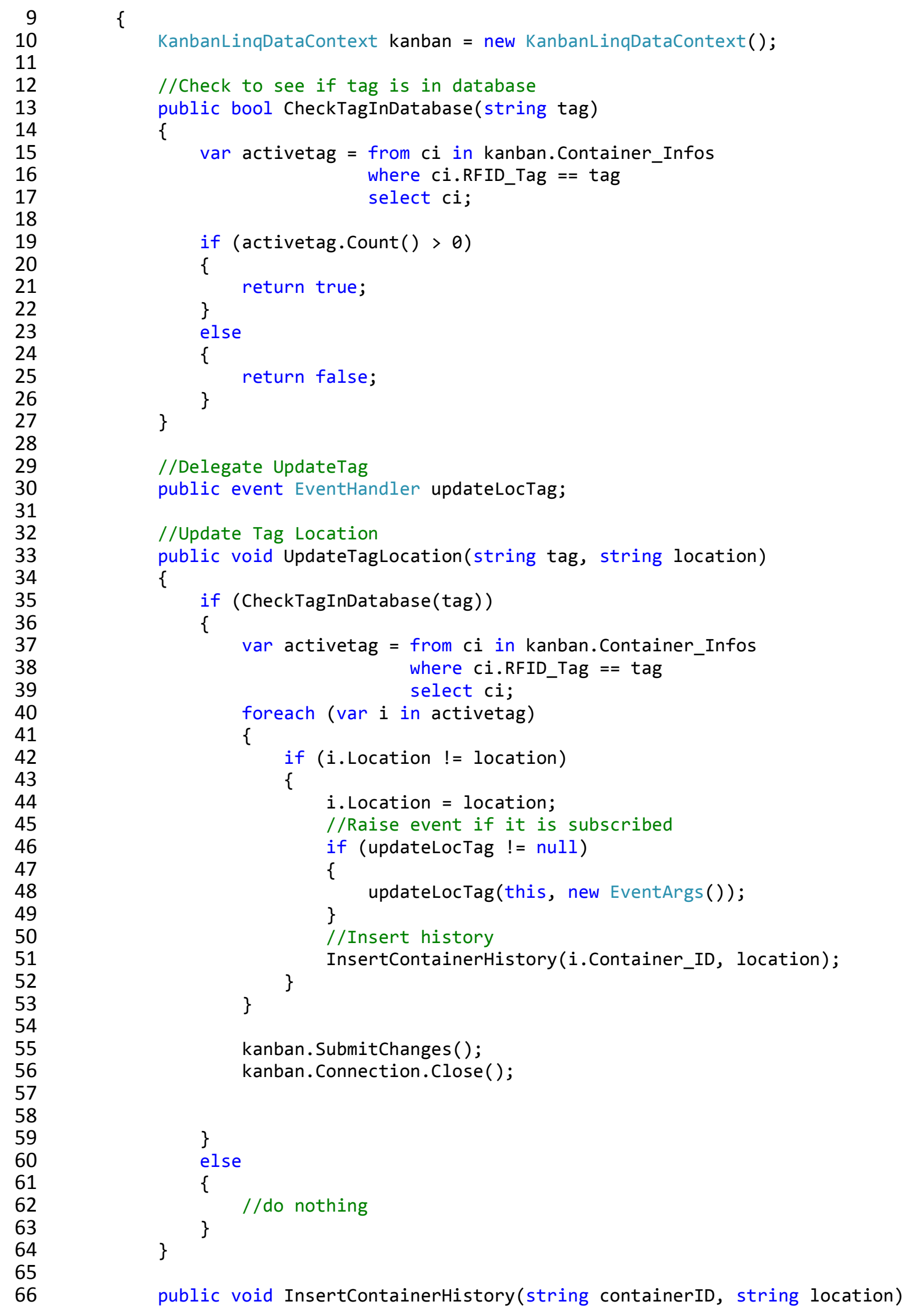


67

68

69

70

71

72

73

74

75

76

77

78

79

80

\section{\{}

KanbanLinqDataContext $\mathrm{k} 2$ = new KanbanLinqDataContext();

Container_History containerHist $=$ new Container_History () ;

containerHist. ContainerID = containerID;

containerHist. Location = location;

containerHist. Time $=$ DateTime. Now;

k2.Container_Histories. InsertOnSubmit(containerHist);

k2.SubmitChanges();

k2.Connection.Close();

\}

\} 